\title{
Article \\ SH3BP2 Deficiency Ameliorates Murine Systemic Lupus Erythematosus
}

\author{
Kyoko Kawahara ${ }^{1}$, Tomoyuki Mukai ${ }^{1, *(D)}$, Masanori Iseki ${ }^{2}$, Akiko Nagasu ${ }^{1}$, Hajime Nagasu ${ }^{3}$,

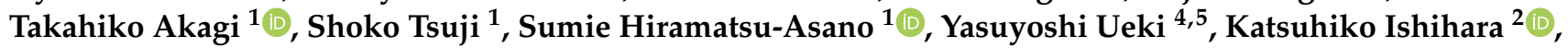 \\ Naoki Kashihara ${ }^{3}$ and Yoshitaka Morita ${ }^{1}$
}

1 Department of Rheumatology, Kawasaki Medical School, Kurashiki 701-0192, Japan; kyoko.k0925@gmail.com (K.K.); yoshida5655@gmail.com (A.N.); akagitahiko@gmail.com (T.A.); shoko7.05.13@gmail.com (S.T.); h061eb@gmail.com (S.H.-A.); morita@med.kawasaki-m.ac.jp (Y.M.)

2 Department of Immunology and Molecular Genetics, Kawasaki Medical School, Kurashiki 701-0192, Japan; miseki@med.kawasaki-m.ac.jp (M.I.); ishihara-im@med.kawasaki-m.ac.jp (K.I.)

3 Department of Nephrology and Hypertension, Kawasaki Medical School, Kurashiki 701-0192, Japan; HajimeNagasu@kms-ndh.com (H.N.); kashinao@med.kawasaki-m.ac.jp (N.K.)

4 Department of Biomedical Sciences and Comprehensive Care, Indiana University School of Dentistry, Indianapolis, IN 46202, USA; uekiy@iu.edu

5 Indiana Center for Musculoskeletal Health, Indiana University School of Medicine, Indianapolis, IN 46202, USA

* Correspondence: mukait@med.kawasaki-m.ac.jp; Tel.: +81-86-462-1111; Fax: +81-86-464-1138

Citation: Kawahara, K.; Mukai, T.; Iseki, M.; Nagasu, A.; Nagasu, H.; Akagi, T.; Tsuji, S.; Hiramatsu-Asano, S.; Ueki, Y.; Ishihara, K.; et al. SH3BP2 Deficiency Ameliorates Murine Systemic Lupus Erythematosus. Int. J. Mol. Sci. 2021, 22, 4169. https:// doi.org/10.3390/ijms22084169

Academic Editor: Laszlo Kovacs

Received: 21 February 2021

Accepted: 16 April 2021

Published: 17 April 2021

Publisher's Note: MDPI stays neutral with regard to jurisdictional claims in published maps and institutional affiliations.

Copyright: (c) 2021 by the authors. Licensee MDPI, Basel, Switzerland. This article is an open access article distributed under the terms and conditions of the Creative Commons Attribution (CC BY) license (https:// creativecommons.org/licenses/by/ $4.0 /)$
Abstract: Background: The adaptor protein Src homology 3 domain-binding protein 2 (SH3BP2) is widely expressed in immune cells. It controls intracellular signaling pathways. The present study was undertaken to investigate the role of SH3BP2 in a murine systemic lupus erythematosus model. Methods: For the lupus model, we used Fas ${ }^{l p r / p r}$ mice. Clinical and immunological phenotypes were compared between Fas ${ }^{l p r / l p r}$ and SH3BP2-deficient Fas ${ }^{l p r / p r}$ mice. Splenomegaly and renal involvement were assessed. Lymphocyte subsets in the spleen were analyzed by flow cytometry. To examine the role of SH3BP2 in specific cells, B cell-specific SH3BP2-deficient lupus mice were analyzed; T cells and bone marrow-derived dendritic cells and macrophages were analyzed in vitro. Results: SH3BP2 deficiency significantly reduced lupus-like phenotypes, presented as splenomegaly, renal involvement, elevated serum anti-dsDNA antibody, and increased splenic $\mathrm{B} 220^{+} \mathrm{CD} 4^{-} \mathrm{CD} 8^{-} \mathrm{T}$ cells. Notably, SH3BP2 deficiency in B cells did not rescue the lupus-like phenotypes. Furthermore, SH3BP2 deficiency did not substantially affect the characteristics of $\mathrm{T}$ cells and macrophages in vitro. Interestingly, SH3BP2 deficiency suppressed the differentiation of dendritic cells in vitro and reduced the number of dendritic cells in the spleen of the lupus-prone mice. Conclusions: SH3BP2 deficiency ameliorated lupus-like manifestations. Modulating SH3BP2 expression could thus provide a novel therapeutic approach to autoimmune diseases.

Keywords: Src homology 3 domain-binding protein 2; systemic lupus erythematosus; lupus mouse model; dendritic cells

\section{Introduction}

Systemic lupus erythematosus (SLE) is an autoimmune disease influenced by genetic and environmental factors and is characterized by dysregulated immune responses such as loss of self-tolerance to cellular antigens and autoantibody production [1]. Autoantibody production causes immune complex formation, resulting in local and systemic inflammation and organ damage [1]. In addition to the involvement of the acquired immune system, the innate immune system also contributes to the induction and progression of SLE [2,3]. The clinical features of SLE have been recapitulated in several animal models [4-7], one of which is MRL-Fas ${ }^{l p r / l p r}$ mice, which carry a loss-of-function mutation in the death-receptor, Fas/CD95 [6]. The Fas mutation results in decreased Fas-mediated apoptosis of autoreactive 
lymphocytes and subsequent accumulation of these cells [8]. The lupus-prone mice develop massive lymphoproliferation and multiple-organ damage associated with increased autoreactive lymphocytes and autoantibodies, such as the anti-double-stranded DNA (dsDNA) antibody and rheumatoid factor (RF) [9].

Src homology 3 domain-binding protein 2 (SH3BP2, also known as 3BP2) is an adapter protein expressed primarily in immune cells, such as myeloid cells [10,11], B cells [12,13], and T cells [14]. SH3BP2 regulates immune-cell functions by interacting with intracellular signaling proteins, including Syk, PLC $\gamma$, Vav, and Src [15-20]. SH3BP2 mutations are identified as being responsible for the genetic disorder cherubism (OMIM \#118400) characterized by jaw-bone destruction [21]. In cherubism, SH3BP2 mutations, such as Pro418Arg mutation, hyperactivate the downstream signaling in a gain-of-function manner via increased SH3BP2 protein [22]. SH3BP2 gain-of-function mutations cause increased activation of macrophages and osteoclasts $[10,23]$. On the other hand, SH3BP2 deficiency has been reported to impair B-cell proliferation in response to BCR ligation [12,13]. Also, we have previously reported that SH3BP2 deficiency suppresses antibody production against type II collagen and markedly prevents the development of arthritis in a collagen-induced arthritis model [24]. However, it has not been determined whether and how the SH3BP2 deficiency suppresses the development of autoimmune diseases other than rheumatoid arthritis.

In this study, we investigated the involvement of SH3BP2 in SLE pathophysiology using SH3BP2-deficient mice and Fas ${ }^{l p r / p r}$ lupus-prone mice. We explored differential phenotypes in immune cell subpopulations isolated from SH3BP2-deficient mice to elucidate potential mechanisms driving SH3BP2-regulated autoimmune responses.

\section{Results}

\subsection{SH3BP2 Deficiency Improves Splenomegaly and Glomerular Proliferative Changes in} Lupus-Prone Mice

SH3BP2 mRNA and protein are ubiquitously expressed in immune cells. The expression levels were examined in individual immune subsets. Quantitative PCR and immunoblot analyses revealed that SH3BP2 mRNA and protein are expressed in T cells, $\mathrm{B}$ cells, macrophages, and dendritic cells. Moreover, the expression levels are relatively higher in B cells, macrophages, and dendritic cells compared to T cells (Figure A1a,b, Appendix A).

To assess the involvement of SH3BP2 in SLE pathogenesis, we generated SH3BP2deficient $\mathrm{Fas}{ }^{l p r / p r}$ mice. We first confirmed that SH3BP2 protein was deleted in the tissues of the SH3BP2-deficient mice (Figure 1a); SH3BP2 protein levels in the tissues were not altered by the Fas ${ }^{l p r / p r}$ mutation (Figure 1a). We observed $S h 3 b p 2^{+/+}, S h 3 b p 2^{\Delta / \Delta}$, Fas ${ }^{l p r / p r}$, and Sh3bp $2^{\Delta / \Delta}$ Fas ${ }^{l p r / p r}$ mice until the age of 35 weeks. Two Fas ${ }^{l p r / p r}$ mice died before the age of 35 weeks, thus we analyzed Sh3bp $2^{+/+}(n=10), \operatorname{Sh} 3 b p 2^{\Delta / \Delta}(n=10), F a s^{l p r / l p r}(n=14)$, and $S h 3 b p 2^{\Delta / \Delta} F a s^{l p r / p r}$ mice $(n=14)$. We found that SH3BP2 deficiency significantly improved splenomegaly in the Fas ${ }^{l p r / p r}$ mice (Figure $1 \mathrm{~b}, \mathrm{c}$ ).

Given that renal involvement is a common feature in Fas ${ }^{l p r / p r}$ mice [7], we analyzed urinary protein levels and histological changes of the kidney. Urinary protein was not increased in the Fas ${ }^{l p r / p r}$ mice at this age (Figure A2a, Appendix A), whereas proliferative glomerular lesions were already present in the kidney of $\mathrm{Fas}{ }^{\mathrm{lpr} / \mathrm{lpr}}$ mice, and the proliferative change was retrieved in Sh3bp $2^{\Delta / \Delta} \mathrm{Fas}$ pr/lpr mice (Figure 1d,e). Glomerular sclerosis scores were not substantially aggravated in both $F a s^{l p r / p r}$ and $S h 3 b p 2^{\Delta / \Delta} F a s^{l p r / l p r}$ mice, and the scores were comparable between the genotypes (Figure A2b, Appendix A). These findings indicated that SH3BP2 deficiency ameliorated the early glomerular damage of lupusprone mice. 
a

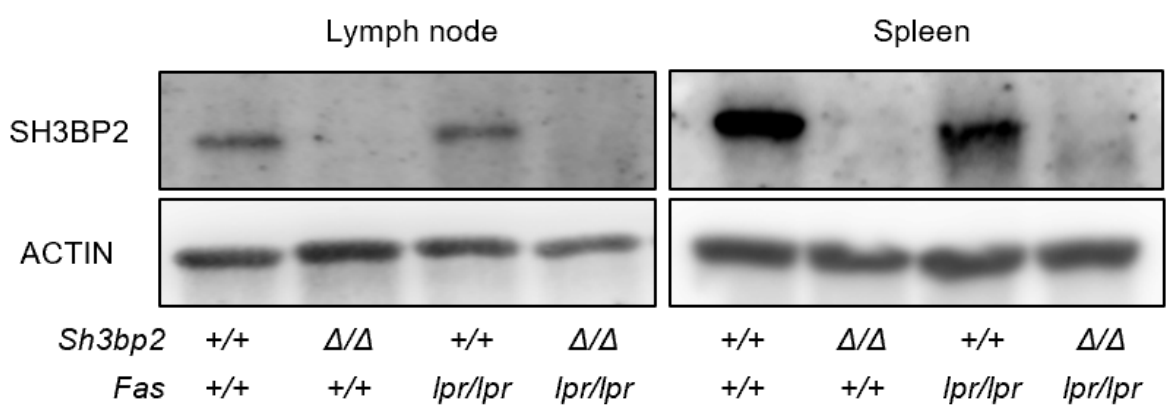

$(75 \mathrm{kDa})$

$(42 \mathrm{kDa})$

b
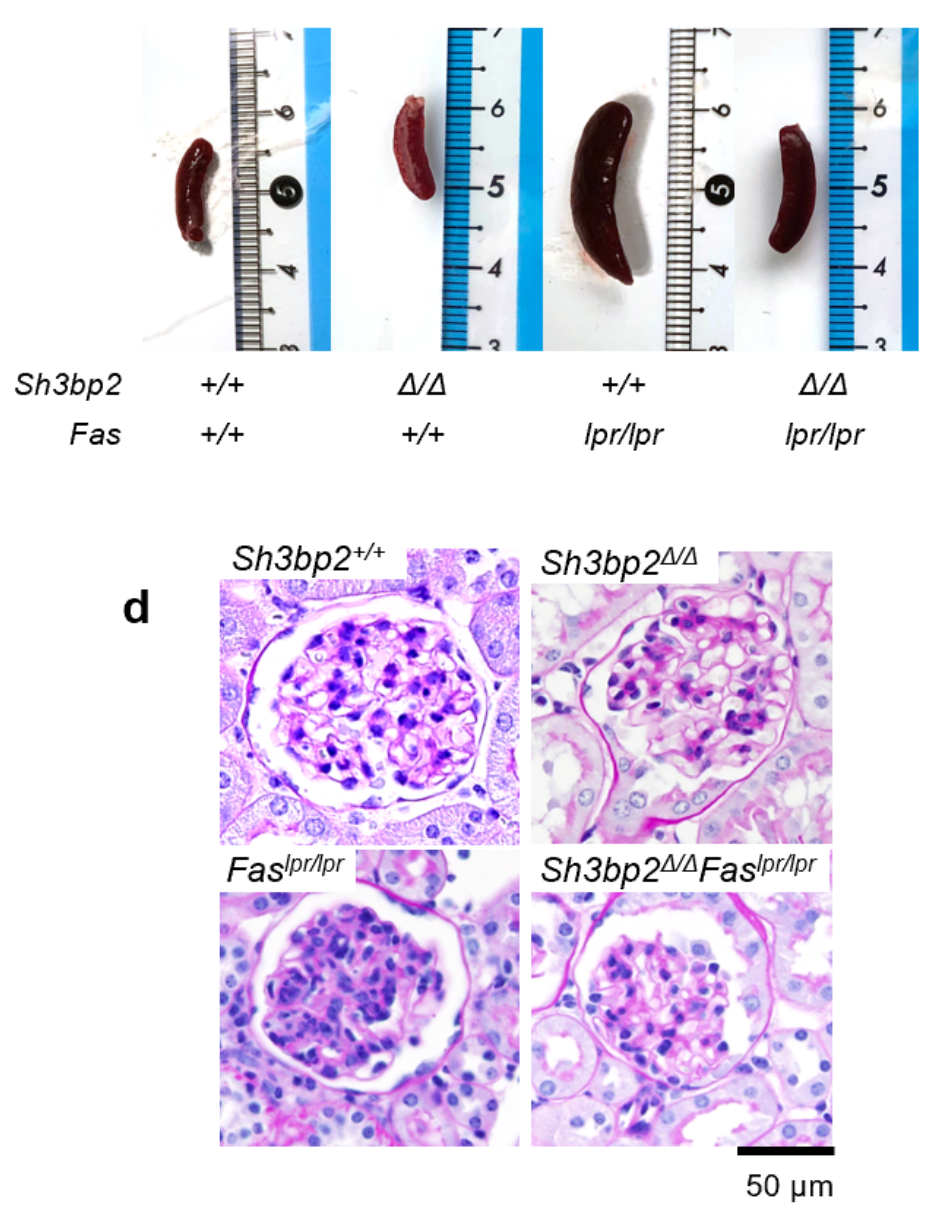

C

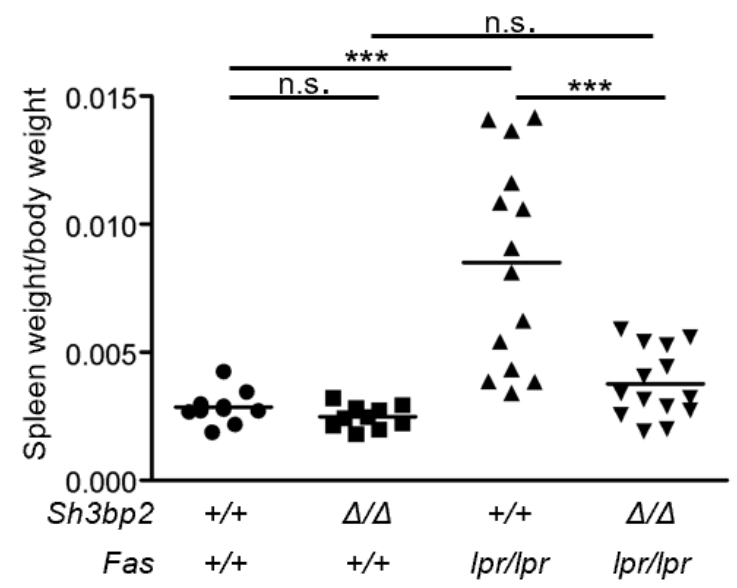

e

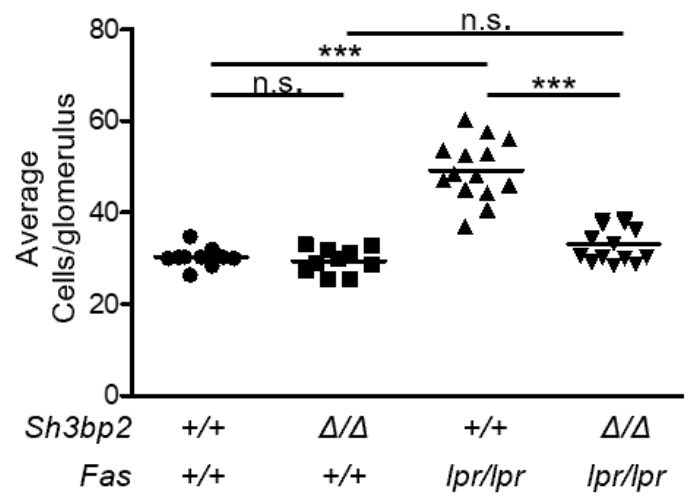

Figure 1. SH3BP2 deficiency improves splenomegaly and the proliferative changes in glomeruli of the Fas ${ }^{l p r / l p r}$ lupus-prone mice. (a) Immunoblot analysis for SH3BP2. Protein samples were collected from lymph nodes and spleens of the indicated mice. SH3BP2 protein levels were determined by western blotting. Actin was used as the loading control. (b-e), Sh3bp2 ${ }^{+/+}$ $(n=10), \operatorname{Sh} 3 b p 2^{\Delta / \Delta}(n=10), F a s^{l p r / p r}(n=14)$, and Sh3bp2 $2^{\Delta / \Delta}$ Fas ${ }^{l p r / p r}$ mice $(n=14)$ were analyzed at the age of 35 weeks. (b) Representative images of the spleen. (c) Spleen weights per body weights were determined. (d) Representative images of periodic acid-schiff (PAS)-stained kidney sections. Original magnification, $400 \times$. Bar, $50 \mu \mathrm{m}$. (e) Quantification of the number of cells in the glomeruli. At least 10 glomeruli per mouse were assessed. The numbers of nuclei in the glomerular cross-sections were counted, and the averages of the nuclei per glomerulus were determined. Each dot denotes an individual mouse, and horizontal lines represent the means. ${ }^{* * *} p<0.001 ;$ n.s. $=$ not significant.

\subsection{SH3BP2 Deficiency Suppresses Autoantibody Production}

Autoantibody production is a critical process associated with the development of organ damage in patients with SLE and lupus-prone mice $[5,25,26]$. We thus determined 
serum concentrations of the anti-dsDNA antibody (IgG) and RF (IgM). Fas ${ }^{l p r / p r}$ mice exhibited elevated levels of serum anti-dsDNA antibody and RF, whereas $S h 3 b p 2^{\Delta / \Delta} F a s^{l p r / l p r}$ mice showed significantly suppressed production of these antibodies (Figure 2a,b). Additionally, we examined the serum immunoglobulin levels. Sh3bp $2^{\Delta / \Delta} F a s^{l p r / p r}$ mice exhibited significantly reduced production of $\operatorname{IgM}$, and $\operatorname{IgG} 2 b$, and total immunoglobulins compared

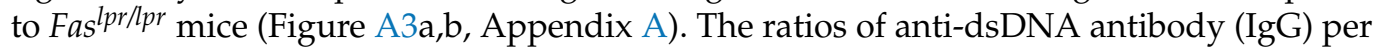
total IgG and RF (IgM) per IgM were significantly decreased in $S h 3 b p 2^{\Delta / \Delta} \mathrm{Fas} / \mathrm{pr} / \mathrm{pr}$ mice compared to those in Fas ${ }^{l p r / p r}$ mice (Figure A3c,d, Appendix A). These data indicate that SH3BP2 deficiency suppressed immunoglobulin production and that the suppression is likely to be predominantly in autoantibody levels.

a

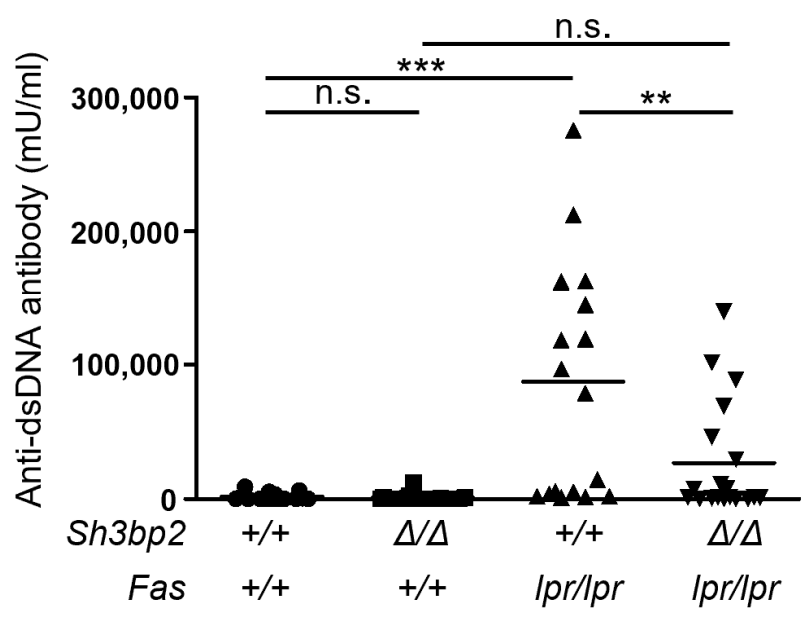

b

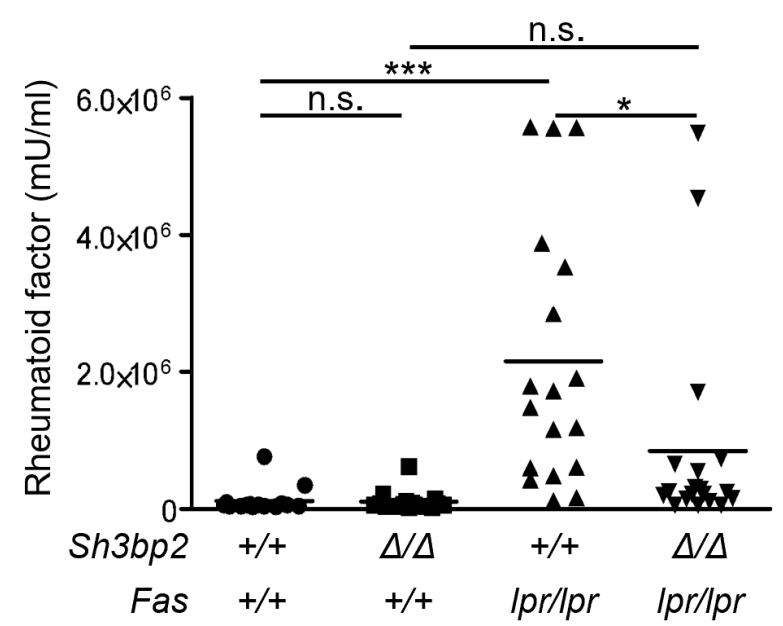

Figure 2. SH3BP2 deficiency suppresses elevated autoantibody production of Fas $\mathrm{lpr} / \mathrm{pr}$ lupus-prone mice. Serum samples

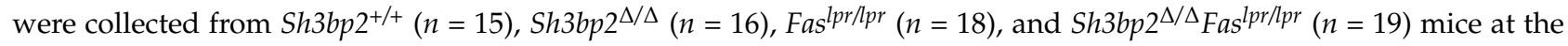
age of 35 weeks. Levels of anti-dsDNA antibody (IgG) (a) and rheumatoid factor (IgM) (b) were determined by ELISA. Each dot denotes an individual mouse, and horizontal lines represent the means. ${ }^{*} p<0.05 ;{ }^{* *} p<0.01 ;{ }^{* *} p<0.001$; n.s. = not significant.

\subsection{SH3BP2 Deficiency Blunts the Aberrant Accumulation of $\mathrm{CD}^{+} \mathrm{B}^{2} 2 \mathrm{O}^{+} \mathrm{CD} 4^{-} \mathrm{CD} 8^{-}$ Double-Negative T (DNT) Cells}

Fas ${ }^{l p r / p r}$ lupus-prone mice are known to exhibit an aberrant pattern of T-cell subsets. One of the prominent subsets is $\mathrm{B}^{2} 2 \mathrm{O}^{+} \mathrm{CD} 4^{-} \mathrm{CD} 8^{-} \mathrm{T}$ cells, referred to as DNT cells [27]. Accumulation of these cells is caused by impaired Fas-mediated apoptosis of autoreactive lymphocytes [28]. Also, Fas ${ }^{l p r / p r}$ mice have been reported to exhibit decreased naïve T cells and increased effector and activated T cells than those of wild-type mice [29]. We thus examined if SH3BP2 deficiency affects DNT cells in Fas ${ }^{l p r / p r}$ mice. The proportion of DNT

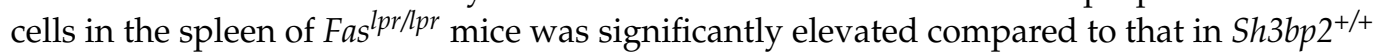
mice (Figure 3a). Interestingly, the aberrant accumulation of DNT cells in the spleen was improved in the $S h 3 b p 2^{\Delta / \Delta}$ Fas ${ }^{l p r / l p r}$ mice (Figure 3a,b).

Next, to examine the activation status of the $\mathrm{CD} 4^{+}$and $\mathrm{CD} 8^{+} \mathrm{T}$ cells, we determined the early activation marker $\mathrm{CD} 69$ expression. Activated $\mathrm{CD} 69^{+} \mathrm{CD} 4^{+} \mathrm{T}$ cells were increased in Fas ${ }^{l p r / l p r}$ mice as previously reported [30], but SH3BP2 deficiency significantly suppressed the activation of $\mathrm{CD} 4^{+} \mathrm{T}$ cells in the spleen (Figure 3c). These findings suggest that the aberrant accumulation of autoreactive and activated $\mathrm{T}$ cells in lupus-prone mice was partly abrogated by SH3BP2 deficiency. 

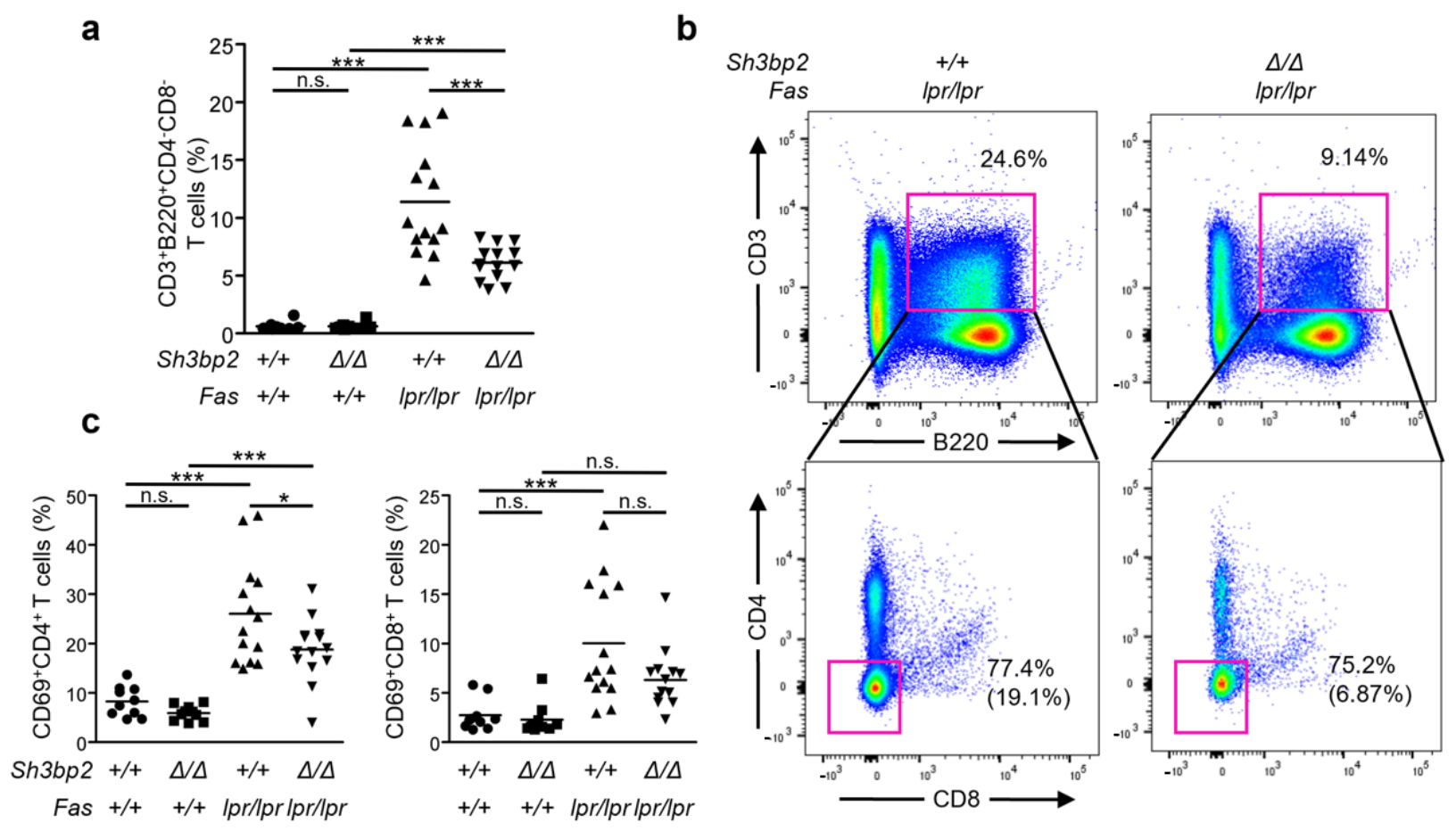

Figure 3. Aberrant accumulation of $\mathrm{CD}^{+} \mathrm{B} 220^{+} \mathrm{CD} 4^{-} \mathrm{CD} 8^{-}$cells is improved in $\mathrm{Sh} 3 \mathrm{bp} 2^{\Delta / \Delta} \mathrm{Fas}{ }^{l p r / p r}$ mice. Spleen cells were

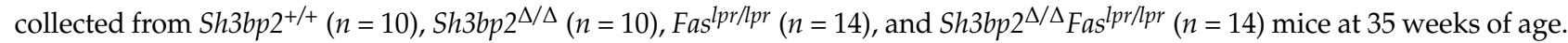
$\mathrm{T}$ cell subsets were stained with fluorochrome-labeled antibodies against CD3, CD4, CD8, B220, and CD69. (a) The ratios of $\mathrm{T}$ cell subsets in the spleen were analyzed by flow cytometry. All the cells were gated on lymphocytes. (b) Representative flow cytometry plots of $\mathrm{CD}^{+} \mathrm{B} 220^{+} \mathrm{CD} 4^{-} \mathrm{CD} 8^{-}$cells (double negative $\mathrm{T}$ (DNT) cells) cells. After gating $\mathrm{CD}^{+} \mathrm{B} 220^{+}$cells, the ratios of $\mathrm{CD}^{-} \mathrm{CD}^{-}$cells are defined as indicated by red rectangles. The numbers in parentheses indicate the percentages of DNT cells in total lymphocytes. (c) The ratios of $\mathrm{CD} 9^{+} \mathrm{CD} 4^{+}$or $\mathrm{CD} 8^{+} \mathrm{T}$ cell subsets were determined. Each dot denotes an individual mouse, and horizontal lines represent the means. ${ }^{*} p<0.05 ;{ }^{* * *} p<0.001$; n.s. $=$ not significant.

\subsection{B Cell-Specific SH3BP2 Deficiency Does Not Improve the Clinical and Immunological Phenotypes}

We hypothesized that SH3BP2 deficiency in B cells suppresses the production of pathogenic antibodies and subsequently ameliorates lupus-like phenotypes in Fas ${ }^{l p r / / p r}$ mice. To this end, we generated conditional B cell-specific SH3BP2-deficient mice and examined if the deletion of SH3BP2 only in B cells improves the lupus-like phenotypes, as observed in the systemic knockout mice.

We confirmed that SH3BP2 protein was deleted specifically in the B cells of the $\mathrm{Cd}_{19} \mathrm{Cre}^{\mathrm{H}} \mathrm{Sh} 3 \mathrm{bp} 2^{\mathrm{fl} / \mathrm{fl}} \mathrm{Fas} \mathrm{S}^{\mathrm{pr} / \mathrm{pr}}$ mice (Figure A4a, Appendix A). We subsequently examined the phenotypes of the conditional knockout mice. Unexpectedly, B cell-specific deletion of SH3BP2 did not improve splenomegaly (Figure A4b,c, Appendix A). Also, B cell-specific SH3BP2 deletion did not ameliorate increased anti-dsDNA antibody levels and aberrant accumulation of DNT cells (Figure A4d,e, Appendix A). These findings indicate that SH3BP2 in B cells does not play a critical role in autoantibody production and development of the lupus-like phenotypes of Fas ${ }^{l p r / p r}$ mice.

\subsection{SH3BP2 Deficiency Does Not Directly Affect the Activation of $\mathrm{CD}^{+} \mathrm{T}$ Cells}

To examine whether SH3BP2 deficiency could affect $\mathrm{CD} 4^{+} \mathrm{T}$ cell activation, $\mathrm{CD} 4^{+}$ $\mathrm{T}$ cells isolated from the spleen were stimulated with immobilized anti-CD3/anti-CD28. We found that there was no difference in the proportion of $\mathrm{CD}^{+} \mathrm{T}$ cells expressing CD69, CD25, CD44, and CD62L between control Sh3bp2 $2^{+/+}$and Sh3bp $2^{\Delta / \Delta}$ mice (Figure A5a, Appendix A). $\mathrm{CD}^{+} \mathrm{T}$ cell proliferation, assessed as carboxyfluorescein succinimidyl ester (CFSE) division, was not affected by SH3BP2 deficiency (Figure A5b, Appendix A). These findings indicate that $\mathrm{SH} 3 \mathrm{BP} 2$ deficiency is unlikely to directly affect $\mathrm{CD} 4^{+} \mathrm{T}$ cell activation. 


\subsection{SH3BP2 Deficiency Modulates Optimal In Vitro Differentiation of Bone Marrow-Derived Dendritic Cells (DCs)}

Since SH3BP2 has been reported to regulate the functions of myeloid cells $[10,24]$, we examined if SH3BP2 deficiency could modulate the activation of macrophages. We found that SH3BP2 deficiency did not alter the expression levels of $C d 80$ and Cd86 mRNA, regardless of Fas ${ }^{l p r / l p r}$ mutation (Figure A6a,b, Appendix A). Also, SH3BP2 deficiency did not affect the responsiveness of macrophages to TLR ligands, represented as Tnf mRNA expression (Figure A6c, Appendix A).

Next, we explored the differentiation of bone marrow cells into DCs. Interestingly, the differentiation into DCs, as determined by CD11c expression, was suppressed in both

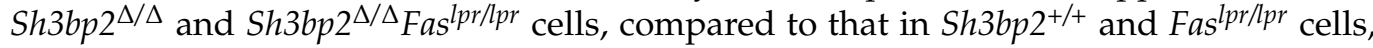
respectively (Figure 4a). The expression of MHC class II, CD80, CD86, and ICAM1 (CD54) gated on $\mathrm{CD}_{11 \mathrm{c}^{+}}$cells was diminished by the SH3BP2 deficiency in some of the CD11 $\mathrm{c}^{+}$ cells (Figure 4a). These data suggest that SH3BP2 deficiency suppressed the differentiation of myeloid precursor cells into DCs.
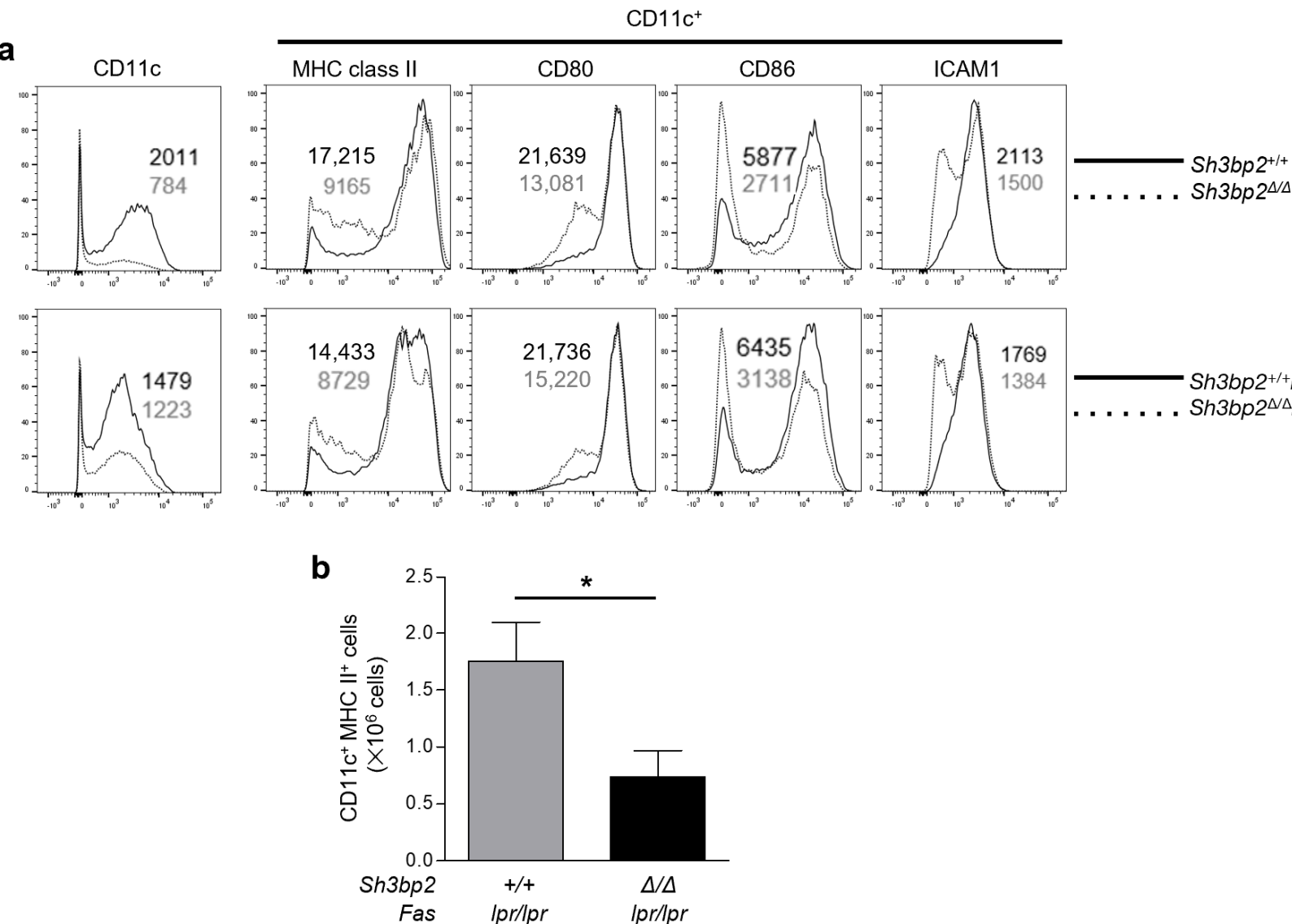

Figure 4. SH3BP2 deficiency suppresses the differentiation of dendritic cells. (a) Flow cytometric analyses of cell sur-

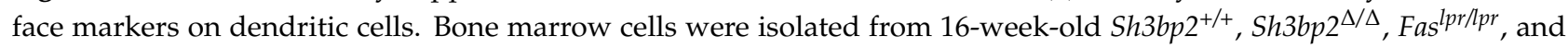
Sh3bp $2^{\Delta / \Delta}$ Fas ${ }^{l p r / p r}$ mice. After a 10-day pre-culture with GM-CSF and IL-4, yielded bone marrow-derived dendritic cells were analyzed by flow cytometry. Representative histograms show the expression levels of CD11c gated on live cells and MHC class II, CD80, CD86, and ICAM1 (CD54) gated on CD11c cells. Data were obtained from at least two independent experiments. Values are the mean fluorescence intensities of the cells. (b) Flow cytometric analyses of the splenic cells. Spleen cells were collected from Fas ${ }^{l p r / l p r}$ and Sh3bp2 $2^{\Delta / \Delta} \mathrm{Fas} / \mathrm{pr} / \mathrm{lpr}(n=3)$ mice at 30 weeks of age and stained with fluorochrome-labeled antibodies against CD11c and MHC class II. Total numbers of CD11 $\mathrm{c}^{+} \mathrm{MHC}$ class $\mathrm{II}^{+}$cells in the spleen were determined. Values are presented as the mean $\pm \mathrm{SD}$. ${ }^{*} p<0.05$.

Furthermore, we explored the effect of SH3BP2 on splenic DCs of the lupus-prone mice. The number of $\mathrm{CD} 11 \mathrm{c}^{+} \mathrm{MHC}$ class $\mathrm{II}^{+}$cells in the spleen was significantly reduced in the 
$S h 3 b p 2^{\Delta / \Delta} F a s^{l p r / l p r}$ mice compared to that in $F a s^{l p r / l p r}$ mice (Figure $4 \mathrm{~b}$ ). This finding suggests that SH3BP2 could regulate lupus-like phenotypes via modulating the differentiation of DCs in the lupus-prone mice.

\section{Discussion}

SH3BP2 protein is ubiquitously expressed in various immune cells and plays critical roles in immune responses [31]. We have previously reported that in a collagen-induced arthritis model, SH3BP2 deficiency suppresses the development of arthritis by reducing the production of anti-type II collagen antibody [24], which was the first evidence showing the involvement of SH3BP2 in an autoimmune disease model. The present study demonstrates that SH3BP2 deletion significantly improves the clinical and immunological phenotypes of lupus-prone $F a s^{l p r / p r}$ mice.

We noted several distinct features of SH3BP2 deficiency in lupus-prone mice. First, germline deletion of SH3BP2 attenuated splenomegaly, glomerular proliferative changes, autoantibody production, and the accumulation of DNT cells. Second, these improved phenotypes were not rescued by B cell-specific deletion of SH3BP2. Third, SH3BP2 deficiency did not directly affect the in vitro activation of $\mathrm{CD} 4^{+} \mathrm{T}$ cells and macrophages. Lastly, SH3BP2 deficiency suppressed the differentiation of myeloid cells into DCs in vitro and reduced the number of splenic DCs in the lupus-prone mice. Collectively, SH3BP2 deficiency improved the lupus-like phenotypes of Fas ${ }^{l p r / p r}$ mice, which is likely caused by SH3BP2-mediated alteration in the myeloid cell differentiation into DCs.

We initially assumed that SH3BP2 in B cells would be essential for its regulatory effect on the pathogenesis of lupus because SH3BP2 has been reported to regulate B-cell functions $[12,13]$. Previous studies have shown that SH3BP2 deletion diminished the intracellular signaling activation, proliferation [12], and in-vivo thymus-independent type 2 antigen response [13]. Additionally, we also have reported that SH3BP2 deficiency suppresses pathogenic antibody production in a murine arthritis model [24]. However, the deletion of SH3BP2 in B cells, unexpectedly, did not retrieve the lupus phenotypes, including aberrant autoantibodies production. The findings indicate that SH3BP2 in B cells has limited effects on the phenotypes of lupus-prone mice. Also, these results suggest that the functional importance of SH3BP2-mediated cellular functions in B cells might vary depending on physiological or pathological conditions.

Our present study has also shown that SH3BP2 deficiency does not influence in vitro activation and proliferation of $\mathrm{CD} 4^{+} \mathrm{T}$ cells. These findings are consistent with previous studies [12,13], in which SH3BP2 deficiency in T cells does not affect proliferation, IL-2 production, and intracellular signaling activation. These findings suggest that SH3BP2 is less likely to directly modulate cellular functions in $\mathrm{CD}^{+} \mathrm{T}$ cells in lupus-prone mice.

Interestingly, SH3BP2 deficiency suppressed in vitro differentiation of DCs from myeloid precursor cells. DCs are the main regulators of innate and adaptive immune responses and play critical roles for initiation, amplification, and perpetuation of various diseases. Multiple studies in humans and mouse models have shown the involvement of DCs in the pathogenesis of lupus [32]. DCs from patients with SLE reportedly display significant phenotypical changes that promote aberrant $\mathrm{T}$ cell function $[33,34]$. Notably, the depletion of DCs in lupus-prone MRL/lpr mice reduces T cell expansion and autoantibody production [35], suggesting that DCs could be potential target cells in the treatment of lupus. In the present study, we demonstrated, for the first time, that the differentiation of DCs is suppressed by the deletion of SH3BP2. We thus propose that SH3BP2-mediated alteration of the differentiation into DCs is a possible mechanism for the improvement of lupus-like phenotypes in Sh3bp2 ${ }^{\Delta / \Delta} \mathrm{Fas}{ }^{l p r / p r}$ mice. Conditional knockout of SH3BP2 in DCs would be necessary to draw a definitive conclusion that proves the direct effects of SH3BP2 deficiency in DCs.

We have previously reported that SH3BP2 P416R gain-of-function mutation, which results in excessive SH3BP2 protein expression, ameliorates clinical and immunological phenotypes of Fas ${ }^{l p r / p r}$ lupus-prone mice [36]. In the study, we have shown that SH3BP2 
gain-of-function mutation suppressed the accumulation of DNT cells, and increased expression of caspase-3 protein and Tnf mRNA in lymph nodes. Based on these findings, we considered that increased TNF expression induces the apoptosis of autoreactive lymphocytes independently of Fas-mediated apoptosis, which is, at least in part, responsible for ameliorating the phenotypes of $F a s^{l p r / p r}$ mice. Interestingly, our present study has shown that SH3BP2 deficiency also ameliorates the lupus-like phenotypes of Fas ${ }^{l p r / p r}$ mice. The seemingly contradictory findings may suggest that different cells are affected by the excess or loss of the SH3BP2 protein. For instance, SH3BP2 gain-of-function significantly augments macrophage inflammatory responses $[10,11,22,37]$, whereas SH3BP2 deficiency do not impact macrophage cellular responses [11,22]. As reported in our previous study [36], increased proapoptotic events mediated by SH3BP2 gain-of-function are considered to ameliorate lupus phenotypes in the Fas ${ }^{l p r / / p r}$ lupus model. Of note, such events, including the expression of Tnf mRNA, were not observed in macrophages from Sh3bp $2^{\Delta / \Delta} \mathrm{Fas}$ lpr/lpr mice in the current study (Figure A6c, Appendix A). These findings suggest that SH3BP2 deficiency has a minimal effect on the cellular functions of macrophages; therefore, probably, the role of SH3BP2 is interchangeable with that of other proteins in macrophages. On the other hand, with respect to DCs, SH3BP2 deficiency plays an essential role in their differentiation, as shown in the current study. Thus, we propose that the differences in the necessity and redundancy of SH3BP2 protein between macrophages and DCs are behind the ameliorated organ damage in both gain- and loss-of-function mice. To dissect the detailed mechanisms, further analyses using cell-specific gain- or loss-of-function mice will be required.

Improved lupus-like phenotypes in SH3BP2-deficient mice led us to consider that the modulation of SH3BP2 expression would be a potential therapeutic approach for SLE. Suppression of SH3BP2 protein levels might improve immunological abnormalities and organ involvement in systemic autoimmune diseases, including SLE. This concept is also supported by our previous findings that SH3BP2 deficiency suppresses the induction of collagen-induced arthritis [24]. From this standpoint, tankyrase can be a therapeutic target to modulate SH3BP2 protein expression. Tankyrase is a poly(ADP-ribose) polymerase that directly binds to SH3BP2 protein and subsequently mediates its degradation [22,38]. Increased tankyrase activity decreases SH3BP2 protein levels. The modulation of tankyrase activity would have therapeutic effects on autoimmune diseases, including SLE. Therefore, further investigations into the cell-specific function and regulation of SH3BP2/tankyrase and the development of a cell-specific targeting approach will be required.

From the clinical standpoint, to understand whether the expression levels of SH3BP2 in immune cells correlate with disease activity and whether SH3BP2 can be a potential prognostic marker is of importance. Although the expression levels of SH3BP2 have not yet been investigated in patients with SLE, the expression patterns of Syk have been analyzed [39]; of note, Syk is the main binding partner of SH3BP2, and SH3BP2 promotes the efficient activation of Syk $[10,20]$. Interestingly a previous study reported that the activation of Syk in B cells was increased in patients with SLE (versus healthy controls), and correlated with disease activity [39]. Therefore, these findings suggest the possible association between the expression levels of SH3BP2 and disease activity. Clinical studies focusing on SH3BP2 would clarify the potential utility of SH3BP2 as a biomarker of SLE.

This study provides a novel insight into the pathological role of SH3BP2 in the immunological mechanisms in SLE. Our current findings warrant further research on developing a novel therapeutic approach to autoimmune diseases by modulating the expression of SH3BP2.

\section{Materials and Methods}

\subsection{Mice}

B6. MRL-Fas ${ }^{l p r / p r}$ mice (\#000482, referred to as Fas ${ }^{l p r / p r}$ mice) and Cd19-Cre mice (\#006785) were obtained from Jackson Laboratory (Bar Harbor, ME, USA). Sh3bp2-floxed mice have been generated by inGenious Targeting Laboratory, as reported previously [40]. 
In the Sh3bp2-floxed mice, Sh3bp2 exon3 is flanked by loxP sites. To generate B cell-specific SH3BP2-deficient mice, the Sh3bp2-floxed mice were crossed with the Cd19-Cre mice. To generate SH3BP2 systemic knockout mice, the Sh3bp2-floxed mice were crossed with EIIaCre mice (\#003724, Jackson Laboratory), in which Cre recombinase is expressed in the germ cells [41]. Elimination of the EIIa-Cre allele was achieved by crossing with mice without the EIIa-Cre allele, resulting in SH3BP2 systemic knockout $\left(S h 3 b p 2^{\Delta / \Delta}\right)$ mice. All mouse studies were performed using male and female mice of the C57BL/6J background. All mutant mice were maintained in the animal facility of Kawasaki Medical School (Okayama, Japan), and were housed in a group ( $2-5$ mice/cage) and maintained at $22{ }^{\circ} \mathrm{C}$ under a $12 \mathrm{~h}: 12 \mathrm{~h}$ light/dark cycle with free access to water and standard laboratory food (MF diet, Oriental Yeast Co., Tokyo, Japan). All animal experiments were approved by the Safety Committee for Recombinant DNA Experiments (Nos.14-32 (7 January 2015), 15-24 (9 October 2015), and 20-28 (2 September 2020)) and the Institutional Animal Care and Use Committee of Kawasaki Medical School (Nos. 17-109 (7 December 2017), 18-105 (13 November 2018), 18-131 (4 February 2019), and 18-132 (4 February 2019)). All experimental procedures were conducted by the institutional and National Institute of Health guidelines for the humane use of animals.

\subsection{Animal Study: Analysis of the Lupus-Prone Mice}

To generate SH3BP2-deficient lupus-prone mice, Fas ${ }^{l p r / p r}$ mice were crossed with

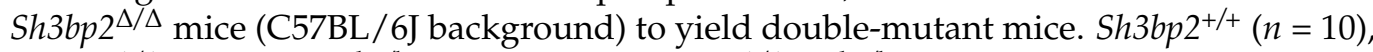
$\operatorname{Sh} 3 b p 2^{\Delta / \Delta}(n=10), F^{l p r}{ }^{l / p r}(n=16)$, and Sh3bp $2^{\Delta / \Delta} F a s^{l p r / p r}(n=14)$ mice were monitored. Two Fas ${ }^{\text {pr/lpr }}$ mice were dead before 35 weeks of age; thus, 14 Fas ${ }^{l p r / l p r}$ mice were analyzed. At the end of the observation period, samples of blood, spleen, and kidney were collected and used for subsequent analyses. Additional serum samples were collected at the same age from mice of another series of observational study, yielding increased sample numbers for serum assays; $\operatorname{Sh} 3 b p 2^{+/+}(n=15), \operatorname{Sh} 3 b p 2^{\Delta / \Delta}(n=16), F^{l p r / l p r}(n=18)$, and Sh3bp $2^{\Delta / \Delta} F a s^{l p r / p r}$ $(n=19)$.

To generate B cell-specific SH3BP2-deficient lupus-prone mice, Fas ${ }^{l p r / p r}$ mice were crossed with $\mathrm{Cd} 19^{\mathrm{Cre} /+} \mathrm{Sh} 3 b p 2^{\text {fllfl }}$ mice (C57BL/6J background). Cd19 ${ }^{\mathrm{Cre} /+} \mathrm{Sh} 3 b p 2^{f l / f l} \mathrm{Fas}{ }^{\mathrm{lpr} / \mathrm{hr}}$ $(n=14)$, and $C d 19^{+/+} S h 3 b p 2^{f l f l f} F a s^{l p r / l p r}(n=14)$ were monitored. One Cd19Cre/+ Sh3bp $2^{f l f l}$ Fas ${ }^{l p r / l p r}$ mouse was dead before 35 weeks of age; thus, $13 \mathrm{Cd}^{\mathrm{C}} \mathrm{9}^{\mathrm{Cre} /+} \mathrm{Sh} 3 \mathrm{bp} 2^{\mathrm{fl} / \mathrm{fl} \mathrm{Fas}} \mathrm{s}^{\mathrm{lpr} / \mathrm{lpr}}$ mice were analyzed. At the end of the observation period, samples of blood, spleen, and kidney were collected and used for subsequent analyses.

Both male and female mice were included in the mouse studies; no sex-differences were observed in the clinical and immunological phenotypes.

\subsection{Western Blot Analysis}

Protein expression in the lymph nodes, spleen, and B cells was determined by western blot, as described previously [36,42]. For the preparation of protein samples, tissues were harvested from 35-week-old mice immediately after euthanasia and soaked in the RIPA lysis buffer (Sigma-Aldrich, St. Lois, MO, USA) containing a protease inhibitor cocktail (P8340, Sigma-Aldrich). The tissues were minced using homogenizers. After centrifugation $\left(15,000 \times g\right.$ at $4{ }^{\circ} \mathrm{C}$ for $\left.20 \mathrm{~min}\right)$, supernatants were collected, and protein concentrations were determined using a BCA protein assay kit (Thermo Fisher Scientific, Waltham, MA, USA). Protein samples were resolved by sodium dodecyl sulfate-polyacrylamide gel electrophoresis and transferred to nitrocellulose membranes. After blocking with 5\% skim milk in Tris-buffered saline with $0.1 \%$ Tween-20, the membranes were incubated with the indicated primary antibodies, followed by incubation with the appropriate horseradish peroxidase (HRP)-conjugated species-specific secondary antibodies. The bands were detected using SuperSignal West Dura or Femto chemiluminescent substrate (Thermo Fisher Scientific) and visualized using an ImageQuant LAS-4000 (GE Healthcare, Little Chalfont, UK). Actin was used as a loading control to normalize the amount of protein. The antibodies used in 
this study were as follows: mouse anti-SH3BP2 monoclonal antibody (clone1E9; Abnova, Taipei City, Taiwan) and rabbit anti-Actin polyclonal antibody (A2066; Sigma-Aldrich).

\subsection{Isolation of Mouse Primary T Cells and B Cells}

Mouse $\mathrm{CD}^{+}$and $\mathrm{CD} 8^{+} \mathrm{T}$ cells and $\mathrm{B}$ cells in spleen were isolated using a $\mathrm{CD} 4$ isolation kit II (Miltenyi Biotec, Bergisch Gladbach, Germany), CD8a isolation kit II (Miltenyi Biotec), and Pan-B cell isolation kit II (Miltenyi Biotec) by negative selection, respectively. A purity rate of $>96.6 \%$ for isolated $\mathrm{CD} 4^{+}$and $\mathrm{CD}^{+} \mathrm{T}$ cells and $\mathrm{B}$ cells was confirmed by flow cytometry [43].

\subsection{Urinary Protein Assessment}

Spot urine samples were collected from 35-week-old mice. Proteinuria was individually evaluated by using urine test strips (Albustix; Siemens Healthineers, Tokyo, Japan), as described [36]. Levels of proteinuria were semi-quantitatively graded from \pm to $3+( \pm$, $<30 \mathrm{mg} / \mathrm{dL} ; 1+, 30-99 \mathrm{mg} / \mathrm{dL} ; 2+, 100-299 \mathrm{mg} / \mathrm{dL} ; 3+, 300<\mathrm{mg} / \mathrm{dL})$.

\subsection{Histopathologic Assessment of Kidney}

The kidneys were fixed in $4 \%$ paraformaldehyde for 2 days and then embedded in paraffin. Kidney sections $(2 \mu \mathrm{m})$ were stained with periodic acid-Schiff (PAS). Glomerular pathology was assessed on 10 glomerular cross-sections per kidney, and the number of nuclei per glomerulus was calculated to determine glomerular cell hyperproliferation [44]. In each group, the percentage of those exhibiting segmental sclerosis was determined and expressed as glomerular sclerosis index, as reported previously with some modification [45]. Glomerular sclerosis was graded semiquantitatively in each glomerulus using a scale of 0 to 4 : 0 , no glomerular sclerosis; 1 , mesangial matrix expansion; 2 , segmental glomerular sclerosis in $<25 \%$ of glomeruli; 3 , segmental glomerular sclerosis in $25 \%$ to $50 \%$ of glomeruli; and 4 , segmental glomerular sclerosis in $>50 \%$ of glomeruli. The mean score per glomerulus was determined for each mouse.

\subsection{Enzyme-Linked Immunosorbent Assay (ELISA) for Serum Anti-dsDNA Antibody and IgM-RF}

Anti-dsDNA antibody (IgG) and IgM-RF levels in serum samples were measured by using ELISA kits (Shibayagi, Gumma, Japan) [36]. Diluted sera (anti-dsDNA 1:100 or IgM-RF 1:1000) were incubated on dsDNA- or RF-coated ELISA plates at $25{ }^{\circ} \mathrm{C}$ for $2 \mathrm{~h}$. After washing, the plates were incubated with HRP-conjugated goat anti-mouse IgG and anti-mouse IgM, respectively, at $25^{\circ} \mathrm{C}$ for $2 \mathrm{~h}$. Tetramethylbenzidine was used for detection, and optical density at $450 \mathrm{~nm}$ (OD450) was measured using a microplate reader (Varioskan Flash; Thermo Fisher Scientific). Concentrations of anti-dsDNA antibodies (IgG) and IgM-RF were calculated and expressed as $\mathrm{mU} / \mathrm{ml}$.

\subsection{Serum Immunoglobulin Measurement}

Concentrations of isotype-specific immunoglobulins in serum were measured with an ELISA kit, SBA Clonotyping System-C57BL/6-AP (Southern Biotech, Birmingham, AL, USA), as reported [36]. Each well in the 96-well plate was incubated with goat antimouse immunoglobulin $(10 \mu \mathrm{g} / \mathrm{mL})$ as a capture reagent at $4{ }^{\circ} \mathrm{C}$ overnight. Wells were blocked with $1 \%$ bovine serum albumin in phosphate-buffered saline at $25^{\circ} \mathrm{C}$ for $1 \mathrm{~h}$ with gentle shaking. Diluted serum samples were added into the capture antibody-coated wells and incubated at $25^{\circ} \mathrm{C}$ for $1 \mathrm{~h}$ with gentle shaking. The wells were then incubated with alkaline phosphatase (AP)-labeled detection antibodies at $25^{\circ} \mathrm{C}$ for $1 \mathrm{~h}$. After adding p-nitrophenyl phosphate substrate, optical densities were measured at $405 \mathrm{~nm}$ by a microplate reader (Varioskan Flash), and the concentrations of isotype-specific immunoglobulins were determined. 


\subsection{Flow Cytometry for Immune Cell Subsets}

The subsets of immune cells in the spleen were analyzed with a flow cytometer (FACSCanto II; BD Biosciences, Franklin, NJ, USA), as described [36]. Briefly, we first prepared cell suspension by mincing spleen gently between two frosted slides. Red blood cell contamination was minimal and disappeared after treatment with red blood cell lysis buffer (eBioscience, San Diego, CA, USA). To block Fc $\gamma$ R, single-cell suspensions were incubated with the rat anti-mouse CD16/CD32 antibody (2.4G2; BD Biosciences) on ice for $10 \mathrm{~min}$ before staining with the indicated monoclonal antibodies. The following monoclonal antibodies were used in this study: rat anti-mouse/human CD45R/B220 (RA36B2), rat anti-mouse CD4 (RM4-4), rat anti-mouse CD8a (53-6.7), Armenian hamster antimouse CD69 (H1.2F3, all from BioLegend, San Diego, CA, USA), and Armenian hamster anti-mouse/human CD3 (145-2C11, eBioscience,); all antibodies were conjugated with fluorochrome. Dead cells were excluded by 7-aminoactinomycyn D (7-AAD; BioLegend) staining. In most samples, a minimum of $3 \times 10^{4}$ events were evaluated, with all data analyzed using Flowjo software (version 10.6.1; BD Biosciences).

\subsection{Functional Analyses of $\mathrm{CD} 4^{+} \mathrm{T}$ Cells}

$\mathrm{CD}^{+} \mathrm{T}$ cells were isolated from the spleen of 12 -week-old mice by negative selection using the $\mathrm{CD}^{+} \mathrm{T}$ Cell Isolation Kit (Miltenyi Biotec) according to the manufacturer's instructions. Purified T cells were activated by plate-bound Armenian hamster anti-mouse CD3 antibody (145-2C11, 5 to $20 \mu \mathrm{g} / \mathrm{mL}$; TONBO biosciences, San Diego, CA, USA) and/or golden Syrian hamster anti-mouse CD28 antibody (37.51, $2 \mu \mathrm{g} / \mathrm{mL}$; TONBO biosciences) at $37^{\circ} \mathrm{C}$ in RPMI 1640 medium containing $10 \%$ heat-inactivated fetal bovine serum (FBS) and $0.05 \mathrm{mM} 2$-mercaptoethanol.

After the activation for $24 \mathrm{~h}$, the cells were collected and stained for activation marker proteins on the cell surface using specific fluorophore-conjugated antibodies; rat antimouse CD4 (RM4-4), rat anti-mouse CD25 (PC61), rat anti-mouse CD62L (MEL-14), rat anti-mouse/human CD44 (IM7), and Armenian hamster anti-mouse CD69 (H1.2F3, all from BioLegend). For proliferation assessment, cells were stained with $1 \mu \mathrm{M}$ carboxyfluorescein succinimidyl ester (CFSE; Dojindo laboratories, Kumamoto, Japan) in the dark at $25^{\circ} \mathrm{C}$ for $10 \mathrm{~min}$ and were activated by plate-bound anti-CD3 antibody and/or anti-CD28 antibody for $72 \mathrm{~h}$. Cells were collected at indicated time points and stained with a fluorophoreconjugated anti-CD4 antibody. All samples were analyzed in a flow cytometer (FACSCanto II) and Flowjo software.

\subsection{Generation of Dendritic Cells (DCs) from Bone Marrow Cells}

DCs were generated in vitro from bone marrow cells of 16-week-old mice, as described previously [36], with some modifications. Briefly, bone marrow cells were flushed from the tibia and femur of the mice; the collected cells were plated at a density of $1 \times 10^{6} / \mathrm{mL}$ and cultured for 10 days in $5 \% \mathrm{CO}_{2}$ at $37{ }^{\circ} \mathrm{C}$ in RPMI1640 medium containing $10 \%$ heat-inactivated FBS, $10 \mathrm{ng} / \mathrm{mL}$ recombinant mouse granulocyte-macrophage colony-stimulating factor (GM-CSF; PeproTech, Rocky Hill, NJ, USA), and $5 \mathrm{ng} / \mathrm{mL}$ mouse interleukin (IL)-4 (PeproTech). The yielded DCs were used in subsequent experiments.

\subsection{Flow Cytometric Analyses of DCs}

After the culture for 10 days with GM-CSF and IL-4, the DCs were collected and stained for marker proteins on the cell surface using specific fluorophore-conjugated antibodies; Armenian hamster anti-mouse CD11c (N418), Armenian hamster anti-mouse CD80 (16-10A1), rat anti-mouse CD86 (GL-1), rat anti-mouse CD54/ICAM1 (YN1/1.7.4, all from BioLegend), and rat anti-mouse MHC Class II (I-A/I-E; M5/114.15.2, eBioscience). Splenic cells isolated from 30-week-old mice were stained with Armenian hamster antimouse CD11c (N418, BioLegend) and rat anti-mouse MHC Class II (I-A/I-E; M5/114.15.2, eBioscience). Dead cells were excluded by 7-AAD (BioLegend) staining. All samples were analyzed in a flow cytometer (FACSCanto II) and Flowjo software. 


\subsection{Culture of Bone Marrow-Derived Macrophages}

Isolation and culture of primary bone marrow cells were performed, as previously described [36,37]. Briefly, bone marrow cells were isolated from the long bones of 16-weekold female mice and cultured on Petri dishes for $2 \mathrm{~h}$ at $37^{\circ} \mathrm{C}$ under $5 \% \mathrm{CO}_{2}$. Non-adherent bone marrow cells were re-seeded on culture plates at a density of $1 \times 10^{6}$ cells $/ \mathrm{mL}$ and then incubated for 2 days in $\alpha$-minimum essential medium ( $\alpha$-MEM) containing $10 \%$ heat-inactivated FBS and $25 \mathrm{ng} / \mathrm{mL}$ recombinant mouse macrophage colony-stimulating factor (M-CSF; PeproTech). After the 2-day pre-culture, the yielded bone marrow-derived macrophages were stimulated with Toll-like receptors ligands, such as lipopolysaccharide (LPS, Sigma-Aldrich), polyinosinic-polycytidylic acid sodium salt (Poly(I:C)), single-strand RNA (ssRNA), and CpG oligodeoxynucleotides (ODN, all from InvivoGen, San Diego, CA, USA), for $6 \mathrm{~h}$ in the presence of M-CSF. RNA samples were isolated from bone marrowderived macrophages at the indicated time points and subjected to gene expression analysis.

\subsection{Real-Time Quantitative Polymerase Chain Reaction ( $q P C R$ )}

Total RNA was extracted from culture cells by using RNAiso Plus (Takara Bio, Shiga, Japan) and solubilized in RNase-free water as previously described [23,42]. cDNA was synthesized by using Prime Script RT reagent Kit (Takara Bio). qPCR reactions were performed by using TB Green PCR Master Mix (Takara Bio) with StepOne Plus System (Thermo Fisher Scientific). Gene expression levels relative to Hprt were calculated by $\Delta \Delta \mathrm{Ct}$ method and normalized to control samples indicated in each experiment. The qPCR analysis used following primers; $5^{\prime}$-tcgtctttcacaagtgtcttcag- $3^{\prime}$ and $5^{\prime}-$ ttgccagtagattcggtcttc- $3^{\prime}$ for $C d 80,5^{\prime}$-gaagccgaatcagcctagc- $3^{\prime}$ and $5^{\prime}$-cagcgttactatccegctct$3^{\prime}$ for $C d 86,5^{\prime}$-catcttctcaaaattcgagtgaca- $3^{\prime}$ and $5^{\prime}$-tgggagtagacaaggtacaaccc- $3^{\prime}$ for $T n f, 5^{\prime}$ tcctcctcagaccgctttt- $3^{\prime}$ and $5^{\prime}$-cctggttcatcatcgctaatc- $3^{\prime}$ for Hprt, respectively. All qPCR reactions yielded products with single peak dissociation curves.

\subsection{Statistical Analysis}

Individual values are presented as dots and the means or the means \pm standard deviation. The distribution of the values was assessed by using the Kolmogorov-Smirnov test. Statistical analysis was performed by the two-tailed unpaired Student's $t$-test or Mann-Whitney test to compare two groups and by one-way ANOVA (Tukey post-hoc test) or Kruskal-Wallis test (Dunn's multiple comparison) to compare three or more groups using GraphPad Prism 5 (GraphPad Software, San Diego, CA, USA). $p$ values less than 0.05 were considered statistically significant.

Author Contributions: Conceptualization, K.K., T.M. and Y.M.; methodology, K.K., T.M., M.I., and H.N.; resource, Y.U.; validation, K.K., T.M., M.I., A.N., H.N., T.A., S.T., S.H.-A., Y.U., K.I. and Y.M; formal analysis, K.K. and T.M.; data curation, K.K., T.M., M.I., and H.N.; writing-original draft preparation, K.K., T.M. and Y.M.; writing-review and editing, all authors. All authors have read and agreed to the published version of the manuscript.

Funding: This work was supported in part by grants from JSPS KAKENHI (18K08398 and 21K08484 to T.M., 20K08814 to Y.M.), the National Institute of Health (R01DE025870 and R21AR070953 to Y.U.), Research Project Grants from Kawasaki Medical School (R02G-008 to K.K., R01B-061 to T.M., and 30G-005 to A.N.), the KAWASAKI Foundation for Medical Science and Medical Welfare to K.K. and S.H.A., Japan Rheumatism foundation to K.K., GSK Japan Research Grant to A.N. and S.H.A., Teraoka foundation to T.A. and UCB Japan to T.M.

Institutional Review Board Statement: All animal experiments were approved by the Safety Committee for Recombinant DNA Experiments (Nos.14-32, 15-24, and 20-28) and the Institutional Animal Care and Use Committee of Kawasaki Medical School (Nos. 17-109, 18-105, 18-131, and 18-132). All experimental procedures were conducted by the institutional and National Institute of Health guidelines for the humane use of animals.

Informed Consent Statement: Not applicable. 
Data Availability Statement: Data is contained within the article.

Acknowledgments: We thank M. Yoshimoto, K. Maitani, and A. Kusumoto (Department of Rheumatology, Kawasaki Medical School) for their technical assistance. We are grateful to A. Yoshizaki (Department of Dermatology, University of Tokyo) for helpful discussion and Mizuho Kittaka (Indiana University, Indianapolis, IN, USA) for technical assistance. We are especially grateful to David A. Fox (University of Michigan, Ann Arbor, MI, USA) for critical reading of the manuscript. We are also indebted to the staff at the Research center of Kawasaki Medical School.

Conflicts of Interest: K.K., T.M., A.N., T.A., S.T., S.H.A. and Y.M. receive scholarship donations from AYUMI Pharmaceutical Corporation and Asahi Kasei Corporation. The funders have no role in the design of the study, collection, analyses, or interpretation of data, writing of the manuscript, or in the decision to publish the results.

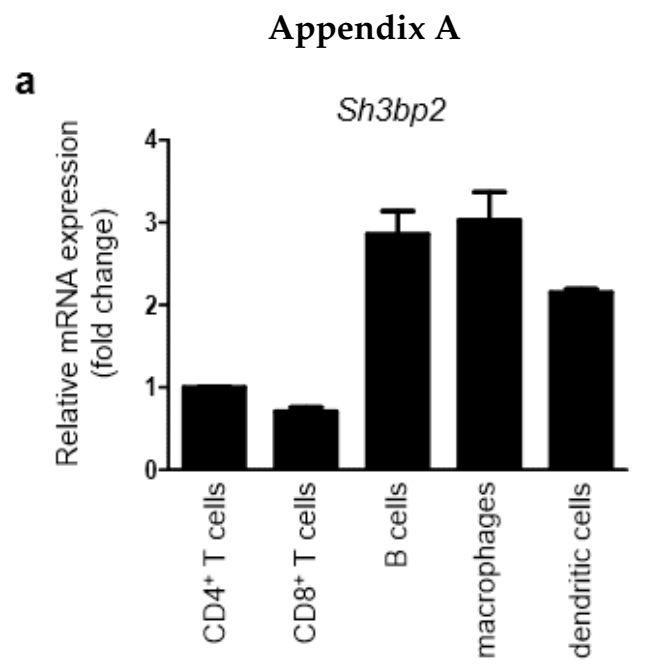

b

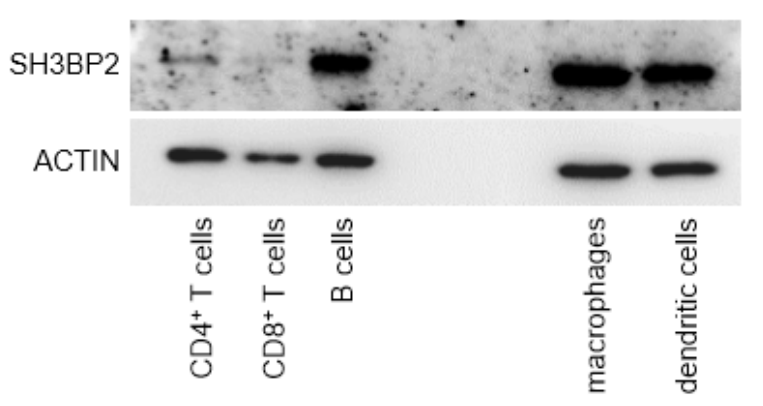

Figure A1. SH3BP2 mRNA and protein expression in immune cells. CD4 ${ }^{+} \mathrm{T}$ cells, $\mathrm{CD} 8^{+} \mathrm{T}$ cells, and B cells were isolated from the spleen of wild-type mice. Macrophages and dendritic cells were differentiated from bone marrow cells of wild-type mice. (a) Quantitative PCR analysis of Sh3bp2. Sh3bp2 mRNA levels relative to that of Hprt were determined in each immune cell and were normalized to the expression level of $\mathrm{CD}^{+} \mathrm{T}$ cells. (b) Immunoblot analysis for SH3BP2 protein. Protein samples were collected from each immune cell subsets. Each protein sample (3.5 $\mu \mathrm{g}$ per lane) were applied to the experiment. SH3BP2 was detected by its specific antibody. ACTIN was used as a loading control.

a

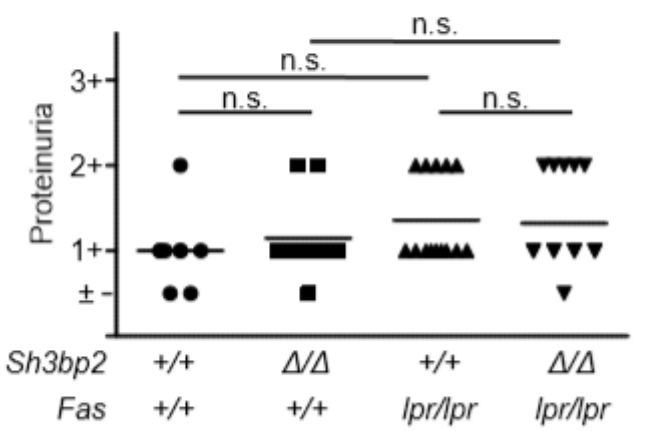

b

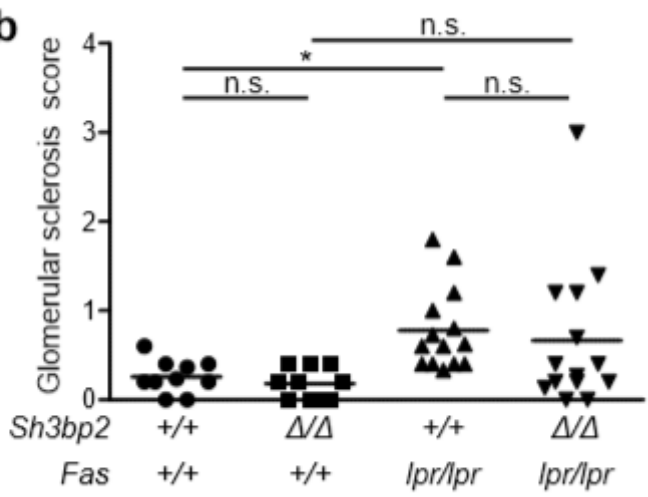

Figure A2. Urinary protein and histologic changes in the SH3BP2-deficient lupus mice. $\operatorname{Sh} 3 b p 2^{+/+}(n=10), \operatorname{Sh} 3 b p 2^{\Delta / \Delta}$ $(n=10), F a s^{l p r / l p r}(n=14)$, and Sh3bp $2^{\Delta / \Delta} \mathrm{Fas}{ }^{l p r / l p r}$ mice $(n=14)$ were analyzed at the age of 35 weeks. (a) Proteinuria of the spot urine samples was evaluated at the age of 35 weeks as follows:,$\pm<30 \mathrm{mg} / \mathrm{dL} ; 1+, 30-99 \mathrm{mg} / \mathrm{dL} ; 2+, 100-299 \mathrm{mg} / \mathrm{dL}$, $3+, 300<\mathrm{mg} / \mathrm{dL}$. (b) Glomerular sclerosis score. More than 5 glomeruli in each kidney section were assessed and the averages were calculated. Each dot denotes an individual mouse, and horizontal lines represent the means. ${ }^{*} p<0.05$; n.s. = not significant. 
a
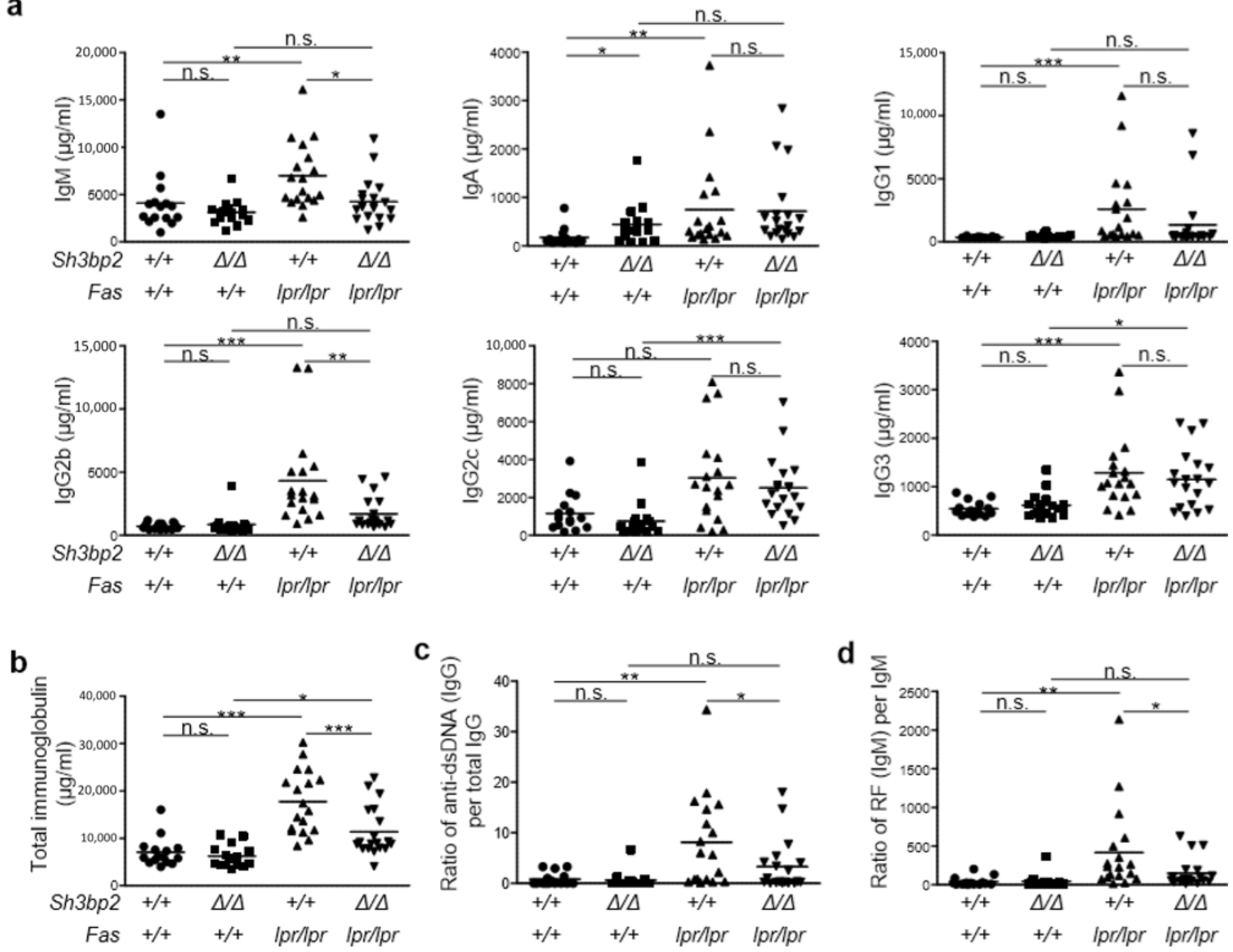

Figure A3. Immunoglobulin subclasses in the SH3BP2-deficient lupus mice. Serum samples were collected from Sh3bp2 $2^{+/+}$ $(n=15), \operatorname{Sh} 3 b 2^{\Delta / \Delta}(n=16), F a s^{l p r / p r}(n=18)$, and Sh3bp $2^{\Delta / \Delta} F^{l p r}{ }^{l / p r}(n=19)$ mice at 35 weeks of age. (a) Levels of each immunoglobulin subclass were determined by ELISA. (b) Total immunoglobulin levels were calculated by summing the concentrations of IgM, IgA, IgG1, IgG2b, IgG2c, and IgG3. (c) The ratio of anti-dsDNA antibody (IgG) per total IgG. (d) The ratio of rheumatoid factor $(\operatorname{IgM})$ per $\operatorname{IgM}$. Each dot denotes an individual mouse, and horizontal lines represent the means. ${ }^{*} p<0.05 ;{ }^{* *} p<0.01 ;{ }^{* * *} p<0.001 ;$ n.s. $=$ not significant. 

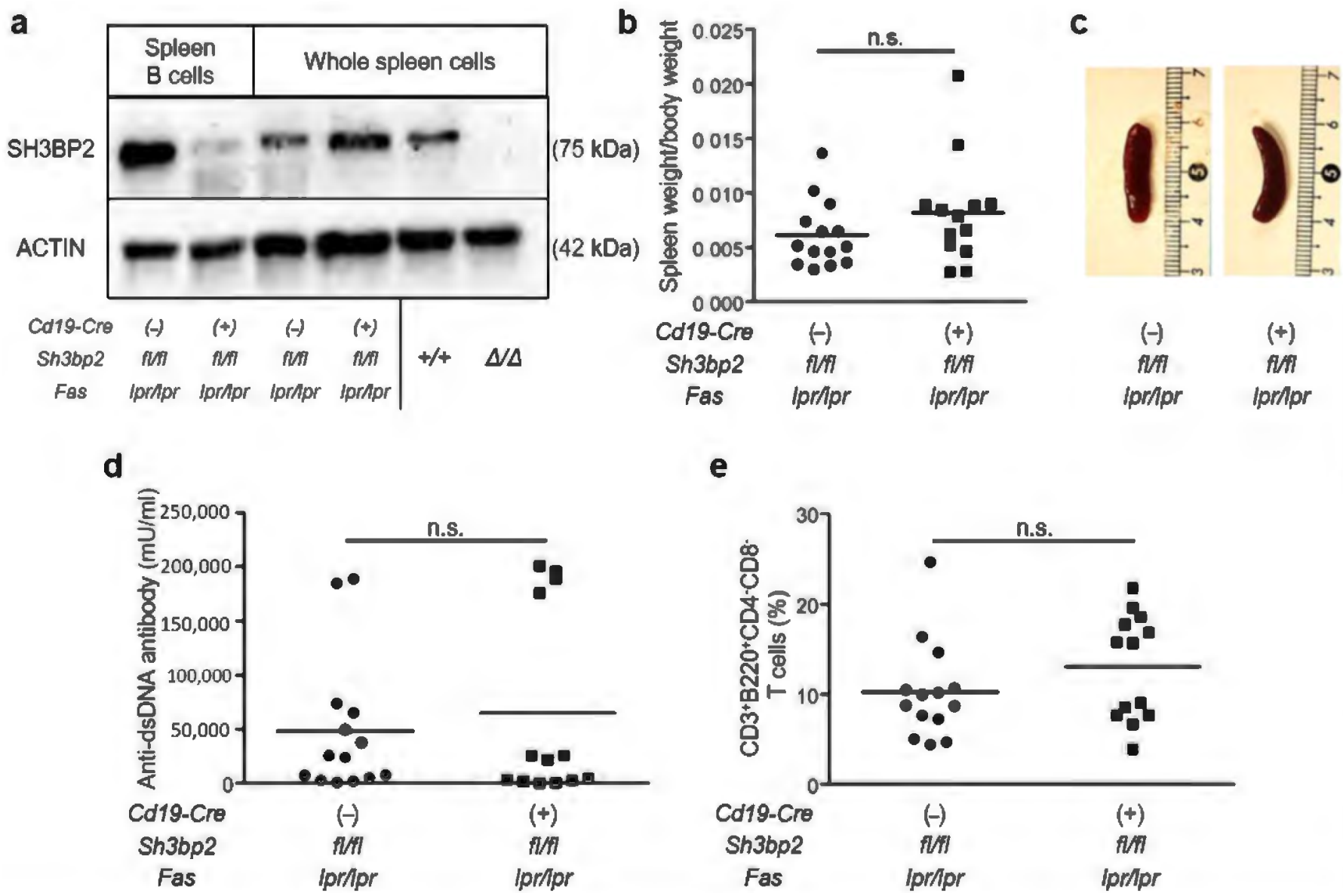

Figure A4. B cell-specific deletion of SH3BP2 does not modulate phenotypes of Fas ${ }^{l p r / p r}$ lupus-prone mice. (a) Immunoblot analysis for SH3BP2. Protein samples were collected from the indicated mice. SH3BP2 protein levels were determined by western blotTable 19. Sh3bp $2^{f l f l} F a s^{l p r / p r}(n=14)$ and $C d 19^{C r e /+} S h 3 b p 2^{f l f l} F a s^{l p r / l p r}(n=13)$ mice were monitored until the age of 35 weeks. (b) At the end of the observation period, spleen weights per body weights were determined. (c) Representative images of the spleens. (d) Levels of serum anti-dsDNA antibody were determined by ELISA. (e) Flow cytometry for T cell subsets in the spleen. The ratios of $\mathrm{CD}^{+} \mathrm{B} 220^{+} \mathrm{CD} 4^{-} \mathrm{CD} 8^{-}$cells (double negative $\mathrm{T}$ (DNT) cells) subsets were analyzed. All the cells were gated on lymphocytes. Each dot denotes an individual mouse, and horizontal lines represent the means. n.s. = not significant. 
a

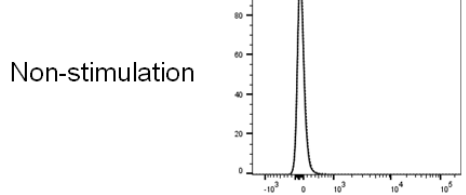

Anti-CD3

$5 \mu \mathrm{g} / \mathrm{ml}$

Anti-CD3

$10 \mu \mathrm{g} / \mathrm{ml}$

$20 \mu \mathrm{g} / \mathrm{ml}$

Anti-CD3/CD28

$10 \mu \mathrm{g} / \mathrm{ml}+2 \mu \mathrm{g} / \mathrm{ml}$
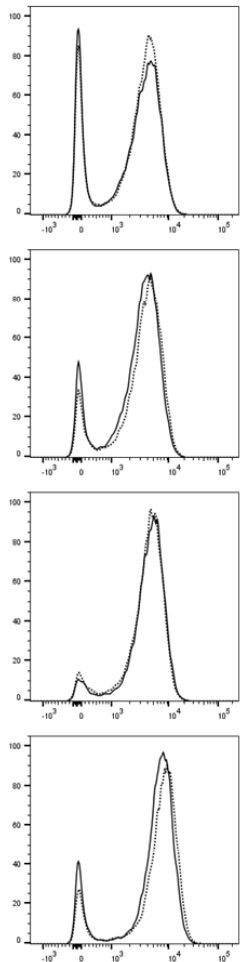

CD69
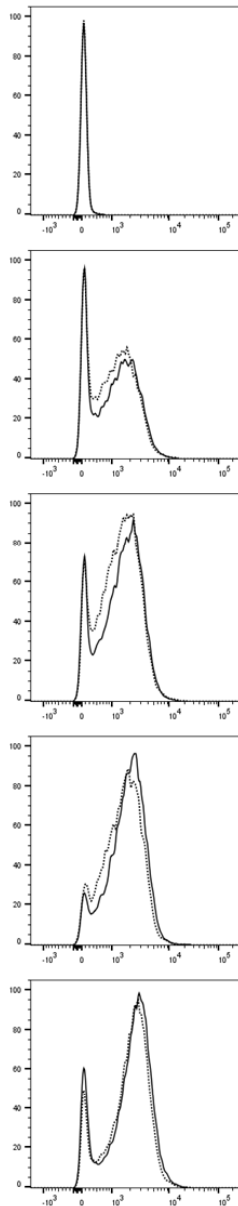

CD25
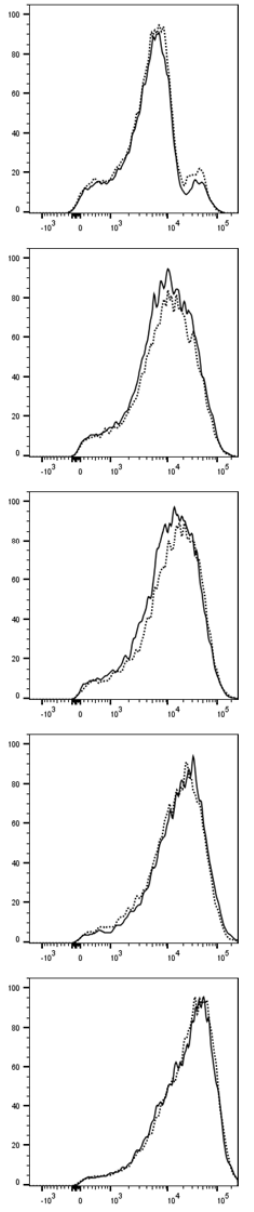

CD44
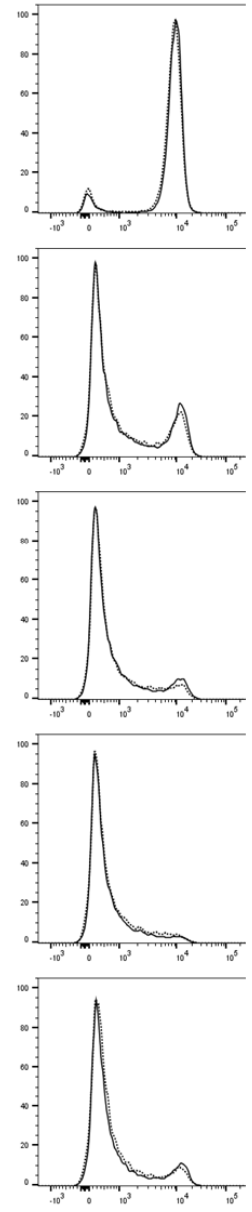

CD62L

b

Non-

Anti-CD3

Anti-CD3 stimulation $5 \mu \mathrm{g} / \mathrm{ml}$

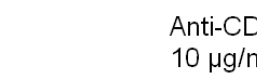

Anti-CD3
$20 \mu \mathrm{g} / \mathrm{ml}$

Anti-CD3/CD28 $10 \mu \mathrm{g} / \mathrm{ml}+2 \mu \mathrm{g} / \mathrm{ml}$

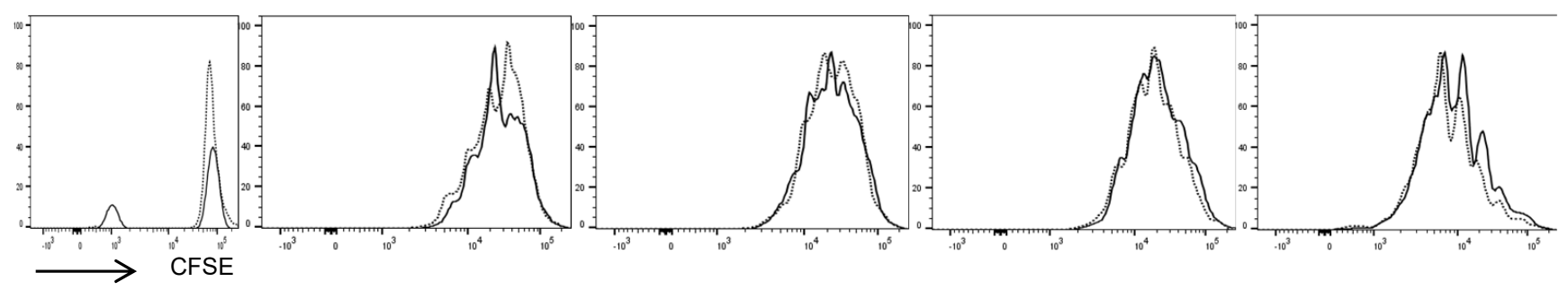

Figure A5. SH3BP2 deficiency does not affect the in vitro activation and proliferation of CD4 ${ }^{+} \mathrm{T}$ cells. (a) Flow cytometry analyses for cell surface protein expression on $\mathrm{CD}^{+} \mathrm{T}$ cells. Isolated $\mathrm{CD} 4^{+} \mathrm{T}$ cells were stimulated with immobilized anti-CD3/anti-CD28 at indicated concentrations for $24 \mathrm{~h}$. (b) In vitro proliferation of $\mathrm{CD}^{+} \mathrm{T}$ cells was measured by CFSE dilution at $72 \mathrm{~h}$ upon stimulation (anti-CD3 and anti-CD28 antibodies). Representative flow cytometry histograms are shown. CFSE, carboxyfluorescein succinimidyl ester. 
a

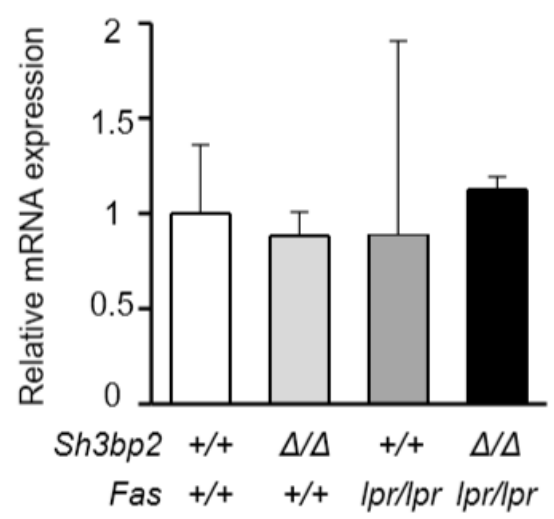

b

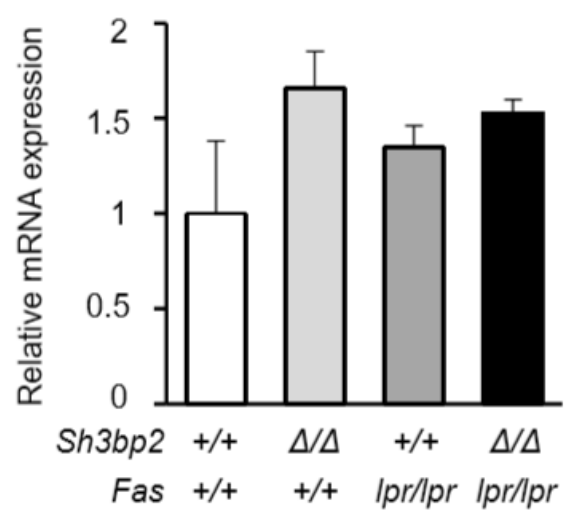

C$$
\text { 흥 }
$$

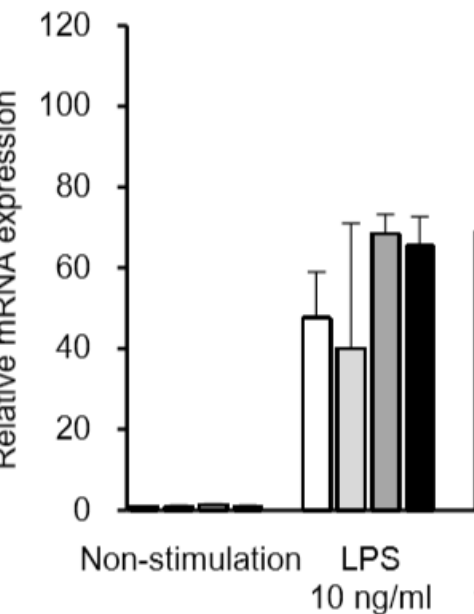

$\operatorname{Tn}$

Tnf

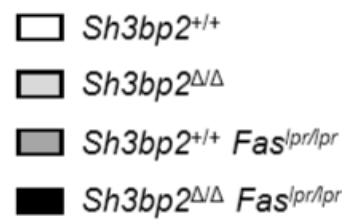

Figure A6. Gene expression patterns in bone marrow-derived macrophages. Bone marrow cells were isolated from the indicated mice and cultured with M-CSF. Gene expression levels in the yielded bone marrow-derived macrophages were determined by quantitative real-time PCR analysis. Expression levels of $C d 80$ (a) and Cd86 (b) at the basal state. (c) Bone marrow-derived macrophages were treated with TLR ligands for $6 \mathrm{~h}$, and Tnf mRNA expression levels were determined. Values are presented as the mean \pm SD. LPS, lipopolysaccharide; poly(I:C), polyinosinic-polycytidylic acid; ssRNA, single-stranded RNA; ODN, oligodeoxynucleotide.

\section{References}

1. Tsokos, G.C.; Lo, M.S.; Costa Reis, P.; Sullivan, K.E. New insights into the immunopathogenesis of systemic lupus erythematosus. Nat. Rev. Rheumatol. 2016, 12, 716-730. [CrossRef] [PubMed]

2. Moulton, V.R.; Suarez-Fueyo, A.; Meidan, E.; Li, H.; Mizui, M.; Tsokos, G.C. Pathogenesis of Human Systemic Lupus Erythematosus: A Cellular Perspective. Trends Mol. Med. 2017, 23, 615-635. [CrossRef] [PubMed]

3. Marian, V.; Anolik, J.H. Treatment targets in systemic lupus erythematosus: Biology and clinical perspective. Arthritis Res. 2012, 14 (Suppl. 4), S3. [CrossRef] [PubMed]

4. Furukawa, F.; Yoshimasu, T. Animal models of spontaneous and drug-induced cutaneous lupus erythematosus. Autoimmun. Rev. 2005, 4, 345-350. [CrossRef]

5. Li, W.; Titov, A.A.; Morel, L. An update on lupus animal models. Curr. Opin. Rheumatol. 2017, 29, 434-441. [CrossRef] [PubMed]

6. Singer, G.G.; Abbas, A.K. The fas antigen is involved in peripheral but not thymic deletion of t-Lymphocytes in t-Cell receptor transgenic mice. Immunity 1994, 1, 365-371. [CrossRef]

7. Du, Y.; Sanam, S.; Kate, K.; Mohan, C. Animal models of lupus and lupus nephritis. Curr. Pharm. Des. 2015, 21, 2320-2349. [CrossRef]

8. Mogil, R.J.; Radvanyi, L.; Gonzalezquintial, R.; Miller, R.; Mills, G.; Theofilopoulos, A.N.; Green, D.R. FAS (CD95) participates in peripheral t-cell deletion and associated apoptosis in-vivo. Int. Immunol. 1995, 7, 1451-1458. [CrossRef] [PubMed]

9. Singer, G.G.; Carrera, A.C.; Marshakrothstein, A.; Martineza, C.; Abbas, A.K. apoptosis, fas and systemic autoimmunity-The mrl-ipr/ipr model. Curr. Opin. Immunol. 1994, 6, 913-920. [CrossRef] 
10. Ueki, Y.; Lin, C.Y.; Senoo, M.; Ebihara, T.; Agata, N.; Onji, M.; Saheki, Y.; Kawai, T.; Mukherjee, P.M.; Reichenberger, E.; et al. Increased myeloid cell responses to M-CSF and RANKL cause bone loss and inflammation in SH3BP2 "cherubism" mice. Cell. 2007, 128, 71-83. [CrossRef]

11. Yoshitaka, T.; Mukai, T.; Kittaka, M.; Alford, L.M.; Masrani, S.; Ishida, S.; Yamaguchi, K.; Yamada, M.; Mizuno, N.; Olsen, B.R.; et al. Enhanced TLR-MYD88 signaling stimulates autoinflammation in SH3BP2 cherubism mice and defines the etiology of cherubism. Cell Rep. 2014, 8, 1752-1766. [CrossRef]

12. de la Fuente, M.A.; Kumar, L.; Lu, B.; Geha, R.S. 3BP2 deficiency impairs the response of B cells, but not T cells, to antigen receptor ligation. Mol. Cell. Biol. 2006, 26, 5214-5225. [CrossRef]

13. Chen, G.; Dimitriou, I.D.; La Rose, J.; Ilangumaran, S.; Yeh, W.C.; Doody, G.; Turner, M.; Gommerman, J.; Rottapel, R. The 3BP2 adapter protein is required for optimal B-cell activation and thymus-independent type 2 humoral response. Mol. Cell. Biol. 2007, 27, 3109-3122. [CrossRef]

14. Dimitriou, I.D.; Lee, K.; Akpan, I.; Lind, E.F.; Barr, V.A.; Ohashi, P.S.; Samelson, L.E.; Rottapel, R. Timed Regulation of 3BP2 Induction Is Critical for Sustaining CD8(+) T Cell Expansion and Differentiation. Cell Rep. 2018, 24, 1123-1135. [CrossRef]

15. Deckert, M.; Tartare-Deckert, S.; Hernandez, J.; Rottapel, R.; Altman, A. Adaptor function for the Syk kinases-interacting protein 3BP2 in IL-2 gene activation. Immunity 1998, 9, 595-605. [CrossRef]

16. Chihara, K.; Kato, Y.; Yoshiki, H.; Takeuchi, K.; Fujieda, S.; Sada, K. Syk-dependent tyrosine phosphorylation of 3BP2 is required for optimal FcRgamma-mediated phagocytosis and chemokine expression in U937 cells. Sci. Rep. 2017, 7, 11480. [CrossRef] [PubMed]

17. Jevremovic, D.; Billadeau, D.D.; Schoon, R.A.; Dick, C.J.; Leibson, P.J. Regulation of NK cell-mediated cytotoxicity by the adaptor protein 3BP2. J. Immunol. (Baltim. Md 1950) 2001, 166, 7219-7228. [CrossRef] [PubMed]

18. Chihara, K.; Kimura, Y.; Honjoh, C.; Yamauchi, S.; Takeuchi, K.; Sada, K. Tyrosine phosphorylation of 3BP2 is indispensable for the interaction with VAV3 in chicken DT40 cells. Exp. Cell Res. 2014, 322, 99-107. [CrossRef]

19. Foucault, I.; Le Bras, S.; Charvet, C.; Moon, C.; Altman, A.; Deckert, M. The adaptor protein $3 B P 2$ associates with VAV guanine nucleotide exchange factors to regulate NFAT activation by the B-cell antigen receptor. Blood 2005, 105, 1106-1113. [CrossRef]

20. GuezGuez, A.; Prod'homme, V.; Mouska, X.; Baudot, A.; Blin-Wakkach, C.; Rottapel, R.; Deckert, M. 3BP2 adapter protein is required for receptor activator of NFkappaB ligand (RANKL)-induced osteoclast differentiation of RAW264.7 cells. J. Biol. Chem. 2010, 285, 20952-20963. [CrossRef] [PubMed]

21. Ueki, Y.; Tiziani, V.; Santanna, C.; Fukai, N.; Maulik, C.; Garfinkle, J.; Ninomiya, C.; doAmaral, C.; Peters, H.; Habal, M.; et al. Mutations in the gene encoding c-Abl-binding protein SH3BP2 cause cherubism. Nat. Genet. 2001, 28, 125-126. [CrossRef] [PubMed]

22. Levaot, N.; Voytyuk, O.; Dimitriou, I.; Sircoulomb, F.; Chandrakumar, A.; Deckert, M.; Krzyzanowski, P.M.; Scotter, A.; Gu, S.; Janmohamed, S.; et al. Loss of Tankyrase-mediated destruction of 3BP2 is the underlying pathogenic mechanism of cherubism. Cell 2011, 147, 1324-1339. [CrossRef]

23. Mukai, T.; Ishida, S.; Ishikawa, R.; Yoshitaka, T.; Kittaka, M.; Gallant, R.; Lin, Y.L.; Rottapel, R.; Brotto, M.; Reichenberger, E.J.; et al. SH3BP2 cherubism mutation potentiates TNF-alpha-induced osteoclastogenesis via NFATc1 and TNF-alpha-mediated inflammatory bone loss. J. Bone Miner. Res. Off. J. Am. Soc. Bone Miner. Res. 2014, 29, 2618-2635. [CrossRef]

24. Mukai, T.; Gallant, R.; Ishida, S.; Kittaka, M.; Yoshitaka, T.; Fox, D.A.; Morita, Y.; Nishida, K.; Rottapel, R.; Ueki, Y. Loss of SH3 domain-binding protein 2 function suppresses bone destruction in tumor necrosis factor-driven and collagen-induced arthritis in mice. Arthritis Rheumatol. (HobokenNj) 2015, 67, 656-667. [CrossRef]

25. Murphy, G.; Lisnevskaia, L.; Isenberg, D. Systemic lupus erythematosus and other autoimmune rheumatic diseases: Challenges to treatment. Lancet (Lond. Engl.) 2013, 382, 809-818. [CrossRef]

26. Zharkova, O.; Celhar, T.; Cravens, P.D.; Satterthwaite, A.B.; Fairhurst, A.M.; Davis, L.S. Pathways leading to an immunological disease: Systemic lupus erythematosus. Rheumatology (Oxf. Engl.) 2017, 56 (Suppl. 1), i55-i66. [CrossRef]

27. Rodriguez-Rodriguez, N.; Apostolidis, S.A.; Fitzgerald, L.; Meehan, B.S.; Corbett, A.J.; Martin-Villa, J.M.; McCluskey, J.; Tsokos, G.C.; Crispin, J.C. Pro-inflammatory self-reactive T cells are found within murine TCR-alphabeta(+) CD4(-) CD8(-) PD-1(+) cells. Eur. J. Immunol. 2016, 46, 1383-1391. [CrossRef]

28. Martina, M.N.; Noel, S.; Saxena, A.; Rabb, H.; Hamad, A.R. Double negative (DN) alphabeta T cells: Misperception and overdue recognition. Immunol. Cell Biol. 2015, 93, 305-310. [CrossRef]

29. Liu, J.; Karypis, G.; Hippen, K.L.; Vegoe, A.L.; Ruiz, P.; Gilkeson, G.S.; Behrens, T.W. Genomic view of systemic autoimmunity in MRLlpr mice. Genes Immun. 2006, 7, 156-168. [CrossRef] [PubMed]

30. Goury, A.; Meghraoui-Kheddar, A.; Belmokhtar, K.; Vuiblet, V.; Ortillon, J.; Jaisson, S.; Devy, J.; Le Naour, R.; Tabary, T.; Cohen, J.H.; et al. Deletion of receptor for advanced glycation end products exacerbates lymphoproliferative syndrome and lupus nephritis in B6-MRL Fas lpr/j mice. J. Immunol. (Baltim. Md 1950). 2015, 194, 3612-3622. [CrossRef] [PubMed]

31. Hatani, T.; Sada, K. Adaptor protein 3BP2 and cherubism. Curr. Med. Chem. 2008, 15, 549-554. [PubMed]

32. Sozzani, S.; Del Prete, A.; Bosisio, D. Dendritic cell recruitment and activation in autoimmunity. J. Autoimmun. 2017, 85, 126-140. [CrossRef] [PubMed]

33. Ding, D.; Mehta, H.; McCune, W.J.; Kaplan, M.J. Aberrant phenotype and function of myeloid dendritic cells in systemic lupus erythematosus. J. Immunol. (Baltim. Md 1950). 2006, 177, 5878-5889. [CrossRef] [PubMed] 
34. Gerl, V.; Lischka, A.; Panne, D.; Grossmann, P.; Berthold, R.; Hoyer, B.F.; Biesen, R.; Bruns, A.; Alexander, T.; Jacobi, A.; et al. Blood dendritic cells in systemic lupus erythematosus exhibit altered activation state and chemokine receptor function. Ann. Rheum Dis. 2010, 69, 1370-1377. [CrossRef]

35. Teichmann, L.L.; Ols, M.L.; Kashgarian, M.; Reizis, B.; Kaplan, D.H.; Shlomchik, M.J. Dendritic cells in lupus are not required for activation of $\mathrm{T}$ and $\mathrm{B}$ cells but promote their expansion, resulting in tissue damage. Immunity 2010, 33, 967-978. [CrossRef]

36. Nagasu, A.; Mukai, T.; Iseki, M.; Kawahara, K.; Tsuji, S.; Nagasu, H.; Ueki, Y.; Ishihara, K.; Kashihara, N.; Morita, Y. Sh3bp2 Gain-Of-Function Mutation Ameliorates Lupus Phenotypes in B6.MRL-Fas(lpr) Mice. Cells 2019, 8, 402. [CrossRef]

37. Mukai, T.; Gallant, R.; Ishida, S.; Yoshitaka, T.; Kittaka, M.; Nishida, K.; Fox, D.A.; Morita, Y.; Ueki, Y. SH3BP2 gain-of-function mutation exacerbates inflammation and bone loss in a murine collagen-induced arthritis model. PLoS ONE 2014, 9, e105518. [CrossRef]

38. Mukai, T.; Fujita, S.; Morita, Y. Tankyrase (PARP5) Inhibition Induces Bone Loss through Accumulation of Its Substrate SH3BP2. Cells 2019, 8, 195. [CrossRef]

39. Iwata, S.; Yamaoka, K.; Niiro, H.; Jabbarzadeh-Tabrizi, S.; Wang, S.P.; Kondo, M.; Yoshikawa, M.; Akashi, K.; Tanaka, Y. Increased Syk phosphorylation leads to overexpression of TRAF6 in peripheral B cells of patients with systemic lupus erythematosus. Lupus 2015, 24, 695-704. [CrossRef]

40. Kittaka, M.; Yoshimoto, T.; Schlosser, C.; Rottapel, R.; Kajiya, M.; Kurihara, H.; Reichenberger, E.J.; Ueki, Y. Alveolar Bone Protection by Targeting the SH3BP2-SYK Axis in Osteoclasts. J. Bone Miner. Res. Off. J. Am. Soc. Bone Miner. Res. 2020, 35, 382-395. [CrossRef]

41. Lakso, M.; Pichel, J.G.; Gorman, J.R.; Sauer, B.; Okamoto, Y.; Lee, E.; Alt, F.W.; Westphal, H. Efficient in vivo manipulation of mouse genomic sequences at the zygote stage. Proc. Natl. Acad. Sci. USA 1996, 93, 5860-5865. [CrossRef] [PubMed]

42. Fujita, S.; Mukai, T.; Mito, T.; Kodama, S.; Nagasu, A.; Kittaka, M.; Sone, T.; Ueki, Y.; Morita, Y. Pharmacological inhibition of tankyrase induces bone loss in mice by increasing osteoclastogenesis. Bone 2018, 106, 156-166. [CrossRef] [PubMed]

43. Hiramatsu-Asano, S.; Sunahori-Watanabe, K.; Zeggar, S.; Katsuyama, E.; Mukai, T.; Morita, Y.; Wada, J. Deletion of Mir223 Exacerbates Lupus Nephritis by Targeting S1pr1 in Faslpr/lpr Mice. Front. Immunol. 2021, 11, 11. [CrossRef]

44. Kikawada, E.; Lenda, D.M.; Kelley, V.R. IL-12 deficiency in MRL-Fas(lpr) mice delays nephritis and intrarenal IFN-gamma expression, and diminishes systemic pathology. J. Immunol. (Baltim. Md 1950) 2003, 170, 3915-3925. [CrossRef] [PubMed]

45. Nagasu, H.; Satoh, M.; Kiyokage, E.; Kidokoro, K.; Toida, K.; Channon, K.M.; Kanwar, Y.S.; Sasaki, T.; Kashihara, N. Activation of endothelial NAD(P)H oxidase accelerates early glomerular injury in diabetic mice. Lab. Investig. A J. Tech. Methods Pathol. 2016, 96, 25-36. [CrossRef] [PubMed] 